\title{
Axial and Centrifugal Compressor Mean Line Flow Analysis Method
}

Joseph P. Veres

Glenn Research Center, Cleveland, Ohio 


\section{NASA STI Program . . . in Profile}

Since its founding, NASA has been dedicated to the advancement of aeronautics and space science. The NASA Scientific and Technical Information (STI) program plays a key part in helping NASA maintain this important role.

The NASA STI Program operates under the auspices of the Agency Chief Information Officer. It collects, organizes, provides for archiving, and disseminates NASA's STI. The NASA STI program provides access to the NASA Aeronautics and Space Database and its public interface, the NASA Technical Reports Server, thus providing one of the largest collections of aeronautical and space science STI in the world. Results are published in both non-NASA channels and by NASA in the NASA STI Report Series, which includes the following report types:

- TECHNICAL PUBLICATION. Reports of completed research or a major significant phase of research that present the results of NASA programs and include extensive data or theoretical analysis. Includes compilations of significant scientific and technical data and information deemed to be of continuing reference value. NASA counterpart of peer-reviewed formal professional papers but has less stringent limitations on manuscript length and extent of graphic presentations.

- TECHNICAL MEMORANDUM. Scientific and technical findings that are preliminary or of specialized interest, e.g., quick release reports, working papers, and bibliographies that contain minimal annotation. Does not contain extensive analysis.

- CONTRACTOR REPORT. Scientific and technical findings by NASA-sponsored contractors and grantees.
- CONFERENCE PUBLICATION. Collected papers from scientific and technical conferences, symposia, seminars, or other meetings sponsored or cosponsored by NASA.

- SPECIAL PUBLICATION. Scientific, technical, or historical information from NASA programs, projects, and missions, often concerned with subjects having substantial public interest.

- TECHNICAL TRANSLATION. Englishlanguage translations of foreign scientific and technical material pertinent to NASA's mission.

Specialized services also include creating custom thesauri, building customized databases, organizing and publishing research results.

For more information about the NASA STI program, see the following:

- Access the NASA STI program home page at http://www.sti.nasa.gov

- E-mail your question via the Internet to help@ sti.nasa.gov

- Fax your question to the NASA STI Help Desk at $443-757-5803$

- Telephone the NASA STI Help Desk at 443-757-5802

- Write to: NASA Center for AeroSpace Information (CASI) 7115 Standard Drive Hanover, MD 21076-1320 


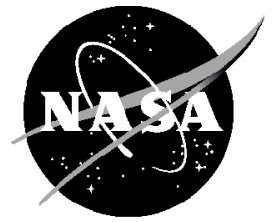

\section{Axial and Centrifugal Compressor Mean Line Flow Analysis Method}

Joseph P. Veres

Glenn Research Center, Cleveland, Ohio

Prepared for the

47th Aerospace Sciences Meeting

sponsored by the American Institute of Aeronautics and Astronautics

Orlando, Florida, January 5-8, 2009

National Aeronautics and

Space Administration

Glenn Research Center Cleveland, Ohio 44135 


\section{Acknowledgments}

The author thanks Dr. Dhanireddy R. Reddy, Chief of the Aeropropulsion Division at the NASA Glenn Research Center and the Subsonic Fixed Wing and the Subsonic Rotary Wing aircraft projects within the NASA Fundamental Aeronautics Program

for supporting this work. The author would also like to thank Mr. John C. Fabian and Mr. Scott Thorp for their support in providing historical data and for managing the refurbishment and buildup effort of the 76-B compressor hardware.

This report contains preliminary findings, subject to revision as analysis proceeds.

This work was sponsored by the Fundamental Aeronautics Program at the NASA Glenn Research Center.

Level of Review: This material has been technically reviewed by technical management.

Available from

NASA Center for Aerospace Information 7115 Standard Drive

Hanover, MD 21076-1320
National Technical Information Service 5285 Port Royal Road Springfield, VA 22161

Available electronically at http://gltrs.grc.nasa.gov 


\title{
Axial and Centrifugal Compressor Mean Line Flow Analysis Method
}

\author{
Joseph P. Veres \\ National Aeronautics and Space Administration \\ Glenn Research Center \\ Cleveland, Ohio 44135
}

\begin{abstract}
This paper describes a method to estimate key aerodynamic parameters of single and multistage axial and centrifugal compressors. This mean-line compressor code COMDES provides the capability of sizing single and multistage compressors quickly during the conceptual design process. Based on the compressible fluid flow equations and the Euler equation, the code can estimate rotor inlet and exit blade angles when run in the design mode. The design point rotor efficiency and stator losses are inputs to the code, and are modeled at off design. When run in the off-design analysis mode, it can be used to generate performance maps based on simple models for losses due to rotor incidence and inlet guide vane reset angle. The code can provide an improved understanding of basic aerodynamic parameters such as diffusion factor, loading levels and incidence, when matching multistage compressor blade rows at design and at part-speed operation. Rotor loading levels and relative velocity ratio are correlated to the onset of compressor surge. NASA Stage 37 and the three-stage NASA 74-A axial compressors were analyzed and the results compared to test data. The code has been used to generate the performance map for the NASA 76-B three-stage axial compressor featuring variable geometry. The compressor stages were aerodynamically matched at off-design speeds by adjusting the variable inlet guide vane and variable stator geometry angles to control the rotor diffusion factor and incidence angles.
\end{abstract}

\section{Introduction}

The mean line flow modeling methodology described in this paper addresses the need for a quick tool for conceptual sizing of compressors during the early phases of the design process of gas turbine engines. This tool can be used to size axial as well as centrifugal compressors either as single stage, or in multistage configurations. The COMDES code which is based on this methodology has a design capability feature that can size the blade angles at the rotor inlet and exit, as well as the stator vane angles. The work distribution in a multistage compressor can be varied by the user. The mean line code has been written to provide rapid evaluation of candidate compressor design concepts.

The ability to model compressor off-design performance is necessary for system evaluation of compressors within gas turbine engines. The off-design performance of the compressor is required to enable engine system analyses at several operating conditions throughout the envelope. The mean line code can be used to do an initial estimate of the variable geometry reset schedule of a multistage compressor that will result in aerodynamically matched stages at off-design compressor speeds. This procedure results in the generation of a compressor characteristic map that can be utilized in a thermodynamic system model of an engine. The compressor map characteristics can often influence the final design of the compressor and therefore compressor sizing, compressor map generation and engine thermodynamic system modeling is an iterative procedure. An example where an engine can have multiple design points are supersonic vehicles, where at the takeoff condition the engine operates at 100 percent design corrected speed and flow rate, while at the cruise condition the engine operates at reduced corrected speed and flow. By knowledge of the performance at off-design conditions, the compressor designer can optimize the configuration to provide acceptable performance in an engine system at all operating conditions. Several validation cases from single and multistage research compressors that were used during the development of the mean line code are included in this report. 


\section{Nomenclature}

$\begin{array}{ll}A & \text { Annular area } \\ a & \text { Speed of sound } \\ B & \text { Axial distance from hub to tip } \\ \text { C } & \text { Absolute velocity } \\ D F & \text { Diffusion factor } \\ g_{c} & \text { Dimensional constant } \\ H & \text { Enthalpy rise } \\ i & \text { Incidence } \\ M & \text { Absolute Mach number } \\ m & \text { Mass flow rate } \\ P & \text { Pressure } \\ \text { Power } & \text { Power } \\ Q & \text { Volume flow rate } \\ \Re & \text { Universal gas constant } \\ R & \text { Radius from centerline of rotor } \\ T & \text { Temperature } \\ U & \text { Rotor peripheral velocity } \\ W & \text { Relative velocity } \\ \alpha & \text { Absolute flow angle } \\ \beta_{F} & \text { Relative flow angle } \\ \beta_{B} & \text { Rotor blade angle } \\ \beta_{V} & \text { Stator vane inlet angle }\end{array}$

$\delta$ Rotor slip factor

$\eta \quad$ Adiabatic efficiency

$\gamma \quad$ Specific heat ratio

$\lambda$ Aerodynamic blockage

$\Phi$ Flow coefficient

$\sigma$ Solidity

\section{Subscripts}

1 Rotor leading edge

2 Rotor trailing edge

3 Stator vane leading edge

4 Stator vane trailing edge

$B$ Rotor blade

$F$ Flow

$H$ Rotor hub

$M$ Meridional component

$R$ Rotor

$T$ Rotor tip

$t$ Total

$S \quad$ Static

$U$ Tangential component

$V$ Stator vane

\section{Methodology}

The methodology is based on the compressible fluid flow equations in Shapiro (Ref. 1), and the Euler equation. The rotor efficiency and stator (or diffusion system) losses at the design point are input items into the code. The design point rotor efficiency is modeled at off-design by an empirical correlation with rotor incidence. The relative velocity ratio and the diffusion factor (Ref. 2 ), through the rotor are correlated to the onset of stall. The equations and variables used in the mean line methodology are listed in the Appendix of this report.

The compressor code can be run either in the design or in the analysis mode. In either mode, the rotor hub and tip radii from the centerline that define the flow path are input at the leading and trailing edges as shown in Figure 1. Other input parameters are the inlet total pressure and temperature, shaft rotational speed, rotor aerodynamic blockages at the inlet and exit and slip factor.

Several of the input parameters depend on whether the code is being run in the design or in the analysis mode. In the design mode, the design point mass flow rate is input and the blade angles at the rotor leading and trailing edges are part of the calculation. The inlet total pressure and temperature are input parameters in either case. In addition to the conditions at the rotor mean line, the hub and tip conditions are also estimated by the code. In the design mode, the rotor exit pressure at the hub, mean and tip are specified as input, and the blade angles at the exit hub, mean and tip are calculated by the code. In both the design and the analysis mode, the conditions at the rotor leading edge are solved by a procedure that iterates on inlet Mach number and the static pressure and temperature.

All of the components of the inlet and exit velocity diagram are solved in a similar iterative manner whether run in the design or in the analysis mode. The fluid properties are determined at each blade leading and trailing edge location from a code named GASPLUS (Ref. 3), which is called as a subroutine by the COMDES code. All of the key components of the rotor inlet velocity diagrams are solved simultaneously using Equations (1) to (12) listed in the Appendix. These parameters are initially 


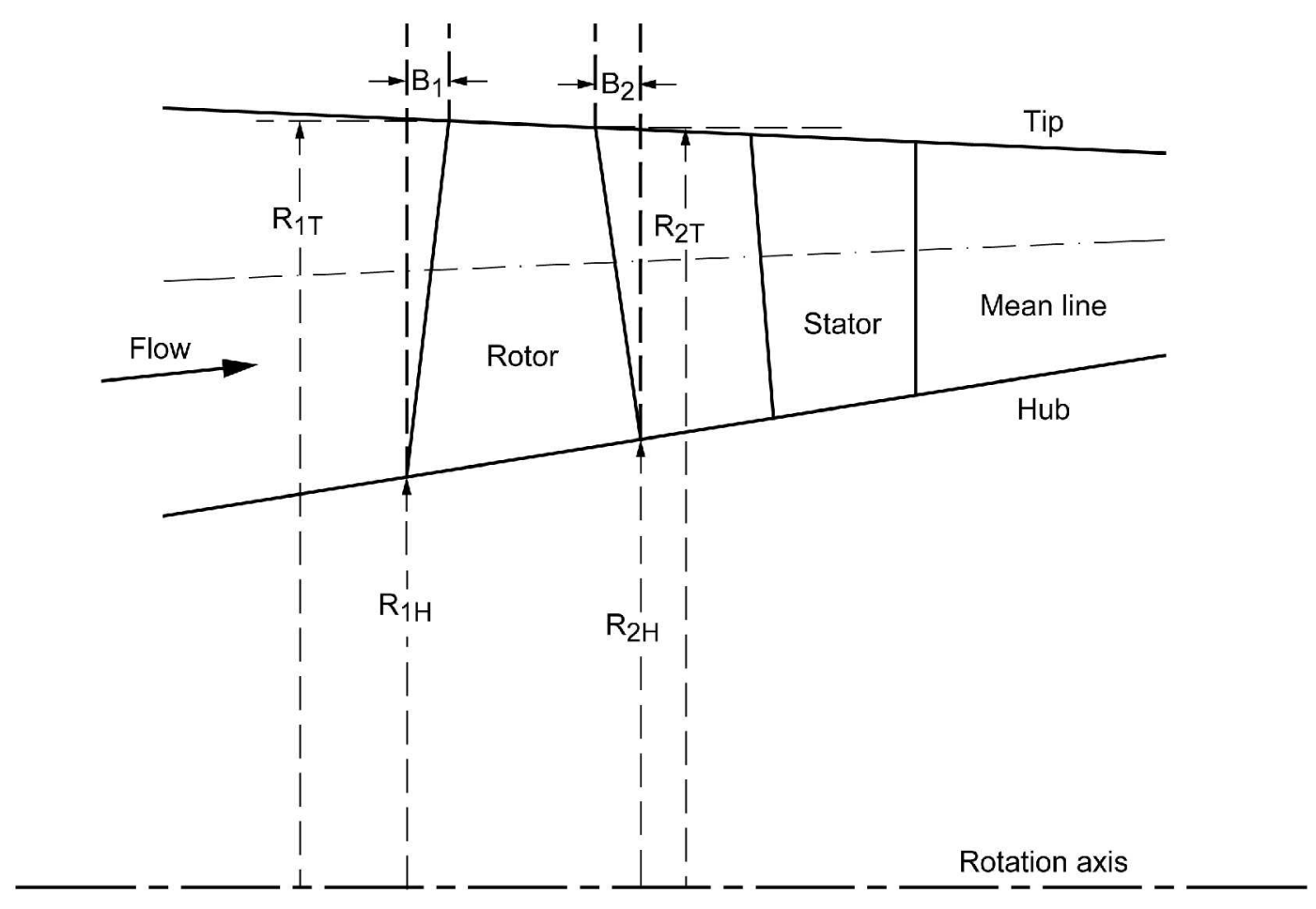

Figure 1.-Axial compressor flow path geometry input parameters to COMDES.

calculated at the mean line radius, followed by estimates of conditions at the end walls. The deviation angle is estimated from the exit flow conditions and the input slip factor. The slip factor for axial compressors as defined by Equation (22) in the Appendix can be on the order of 0.93 to 0.96 and results in the calculation of a rotor deviation angle at the hub, mean, and tip.

\section{Analysis Mode}

In the analysis mode, the rotor blade angles at the leading and trailing edges are specified at the hub, mean, and tip and the mass flow rate and total pressure ratio are calculated parameters. The code calculates the mass flow rate iteratively based on the input value of incidence at the mean blade angle of the first rotor. By this method the mass flow is varied through the compressor by specifying a range of rotor incidences and allowing the code to calculate mass flow rate from choke to stall. Choke is determined as the limit of flow where the code fails to converge on the rotor exit velocity triangles. Surge has been determined empirically from the NASA Stage 37 and the 74-A compressor data correlated to the values of rotor diffusion factor and relative velocity ratios at the tested surge point. At each point along each speed line, the iteration begins with solving for the static pressure and temperature at the rotor leading edge, based on the available area, incidence, mass flow rate and the inlet total pressure and total temperature. Once the inlet Mach number and static pressure and temperature have been solved, all of the components of the absolute and relative velocities and flow angles are determined as shown in Figure 2. Whether run in the analysis or the design mode, the rotor exit deviation angle is taken into consideration in the iterative calculations. As in the design mode, the rotor deviation angle is specified as an input item in terms of a slip factor as defined by Equation (22) in the Appendix. The code calculates all of the components of the rotor exit velocity diagram shown in Figure 2 by solving Equations (13) to (31) in the Appendix simultaneously using an iterative technique. In both the analysis and the design mode, all of the components of velocity at the rotor trailing edge are derived from the enthalpy rise as calculated from Equations (15) and (16) in terms of temperature rise across the rotor, and the Euler equation. 


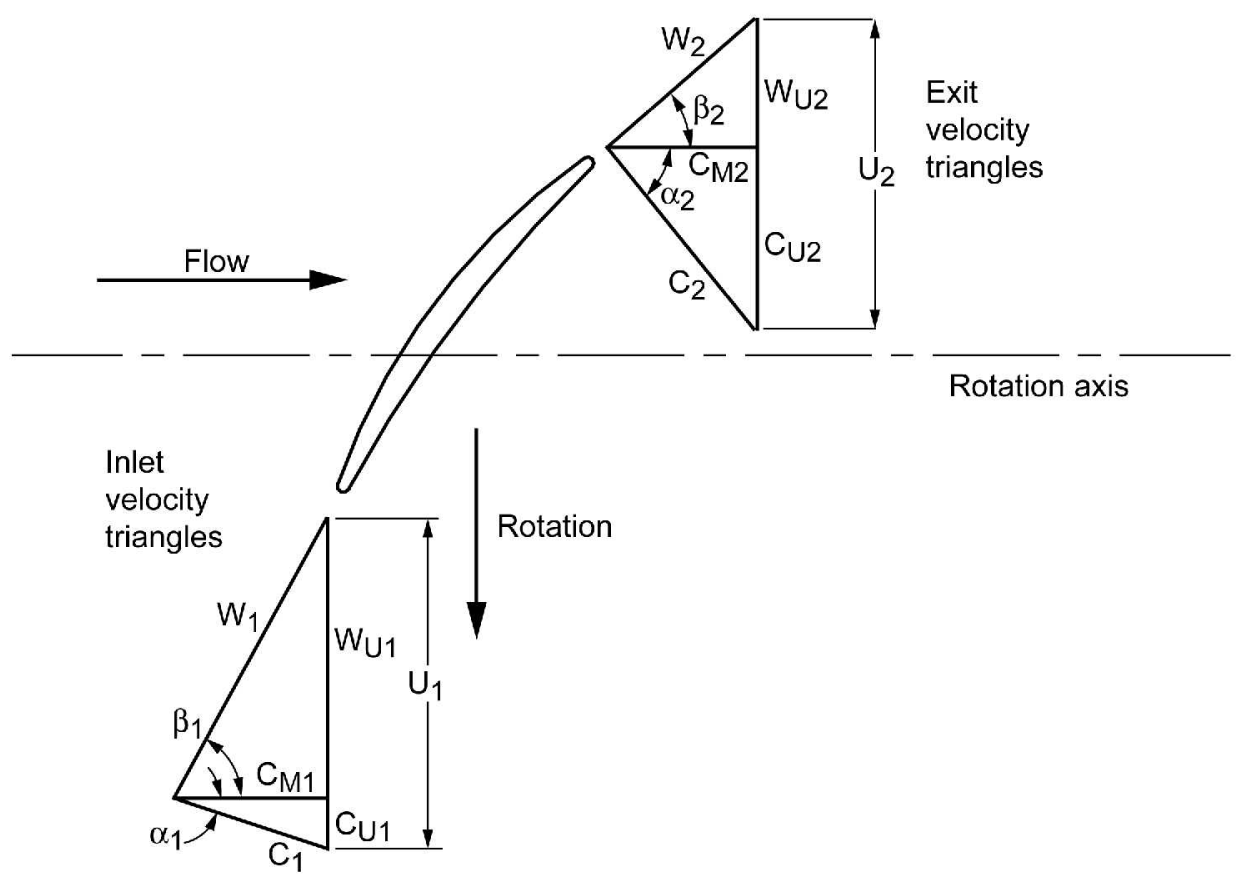

Figure 2.-Rotor inlet and exit velocity diagrams.

The mean line code is run in the analysis mode to estimate the performance of the compressor at offdesign, or part-speed operation. To determine the efficiency at off-design conditions, the compressor rotor efficiency at the design point is input. Note that the design point efficiency is that value only at a rotor incidence of $6^{\circ}$ just ahead of the rotor, not including metal blockage at the leading edge. This design point incidence was also determined empirically from analysis of the test data of the two compressor cases in this report. The "design point" efficiency is assumed to be the same along all speed lines, and is varied only as a function of rotor incidence angle. The losses through the stators due to incidence are not varied directly but are lumped into the efficiency calculation, which is a function of rotor incidence as defined by Equation (31). This is a simplification which assumes that as the flow rate changes along a speed line, both the rotor and the stator experience a change of incidence from their design value, and therefore a reduction in efficiency occurs. A model for stator loss variation with incidence that is separate from the efficiency deration due to incidence of the rotor is planned for a future version of the code.

Varying the inlet guide vane setting angle is the first step in aerodynamically matching a multistage compressor at part-speed operating conditions. The variable guide vane has a large influence on the flow rate into the first rotor. However, variable inlet guide vanes produce a loss of total pressure which is a function of setting angle. The model in the mean line code is an empirical correlation that was derived from the test data of the NASA 74-A compressor featuring flap type guide vanes and is represented by Equation (29).Varying the stator reset angles is the next step in matching multistage compressors, as this can be effective in controlling the incidence in the downstream rotor.

\section{Code Validation Cases}

\section{NASA Stage 37}

The aerodynamic performance of the transonic single stage compressor named NASA Stage 37 (Ref. 4) was simulated with the mean line methodology. Figure 3 illustrates the Stage 37 compressor test data comparison to the mean line model results. The pressure ratio map for a range of speeds and flows from choke to surge is compared to test data in Figure 3(a). The stage efficiency comparison is shown in Figure 3(b). 

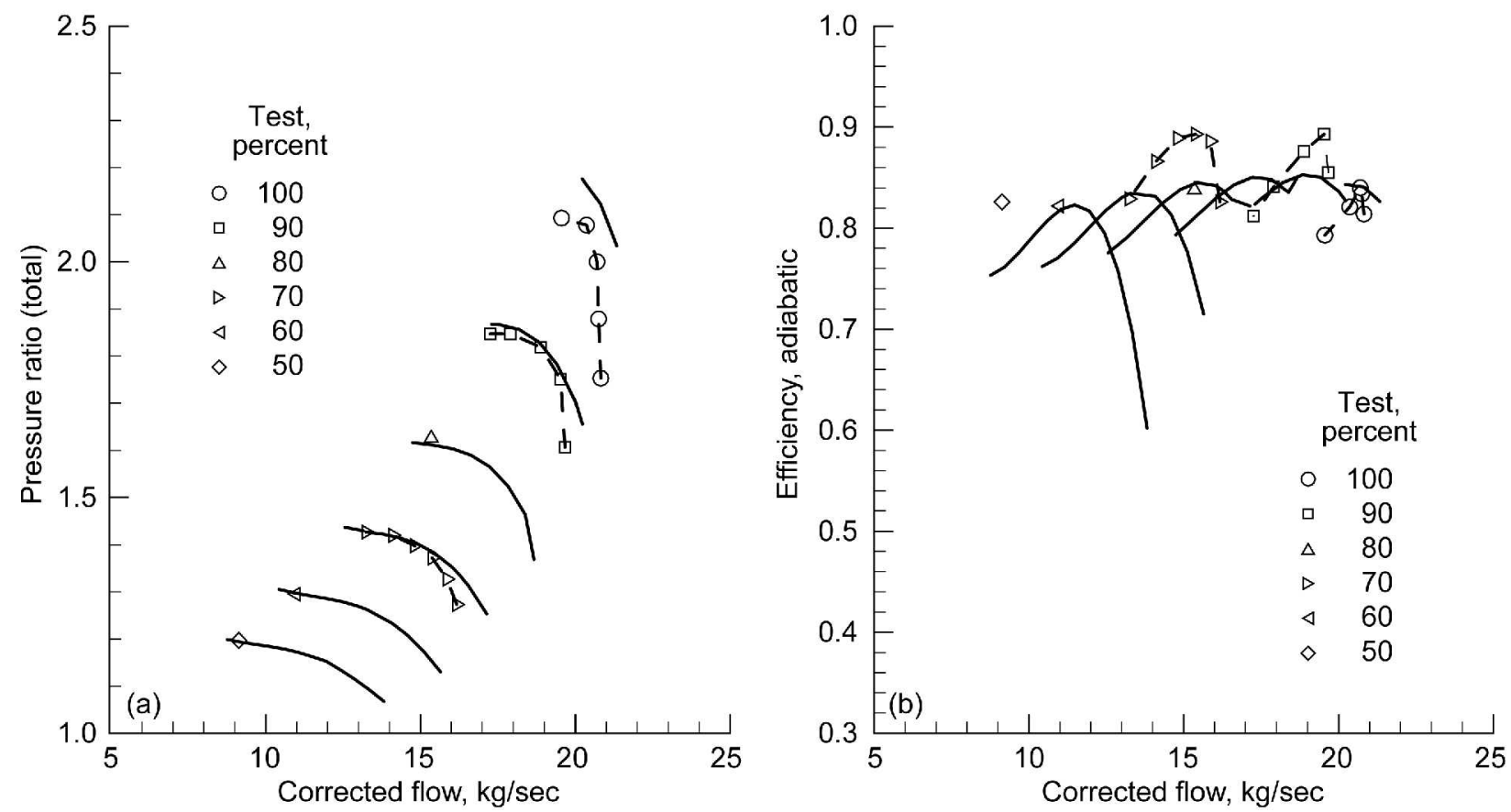

Figure 3.-(a) NASA Stage 37 comparison of mean line model to tested pressure ratio. (b) Efficiency.

TABLE 1.-SLIP FACTOR VERSUS DEVIATION ANGLE AND STAGE PRESSURE RATIO AT 100 PERCENT SPEED AT $21.34 \mathrm{KG} / \mathrm{SEC}$ FLOW RATE

\begin{tabular}{|c|c|c|c|c|}
\hline Slip factor & $\begin{array}{c}\text { Deviation angle, } \\
\text { deg }\end{array}$ & $\begin{array}{c}\text { Exit absolute flow angle, } \\
\text { deg }\end{array}$ & Rotor pressure ratio & Stage pressure ratio \\
\hline 0.90 & 6.6 & 47.2 & 1.99 & 1.94 \\
\hline 0.93 & 4.8 & 49.7 & 2.09 & 2.03 \\
\hline 0.96 & 2.9 & 51.9 & 2.18 & 2.13 \\
\hline
\end{tabular}

Table 1 illustrates the sensitivity of rotor pressure ratio and rotor exit absolute flow angle to the slip factor that is used in the calculation. To obtain agreement with the test data of pressure ratio, a slip factor of 0.93 as defined by Equation (22) was selected to estimate the rotor deviation angle. This value of slip factor resulted in a reasonable match with the tested pressure ratio data at all speed lines except at the $100 \%$ speed line, where it over predicted the pressure ratio. The design point rotor efficiency at the tip, mean and hub were 78.4, 89.4, and 92.9 percent and were input values into the mean line code. The rotor mean incidence angle is 5.0 degrees at a flow rate of $21.34 \mathrm{~kg} / \mathrm{sec}$. The rotor aerodynamic blockages were 2 percent at the inlet and 3 percent at the exit. The stator loss coefficient was 6 percent, as defined by Equation (27). The slip factor, stator loss and aerodynamic blockages were not varied at off design speeds or flow rates in the mean line code.

The mean line compressor flow code was used to calculate the velocity triangles at the rotor leading and trailing edges through a range of flows along each speed line. The pressure ratio versus flow and speed are in good agreement with the test data. The efficiency comparison between the mean line model and the data is good at the 100 percent speed line, but is slightly less than the data at the reduced speed lines. The mean line code output results were analyzed to gain understanding of how the diffusion factor, relative velocity ratio and incidences vary with flow along each speed line.

As one of the key parameters is the variation of mean line rotor incidence along each speed line, knowledge of the range of rotor incidence can be important when matching multistage compressor stages, at all operating speeds. Figure 4(a) shows the variation of rotor incidence as a function of flow coefficient as calculated by the code. The range of rotor incidence is also a function of the corrected speed of the rotor as shown in Figure 4(b) with the lowest range occurring at the higher speeds. At 100 percent speed 

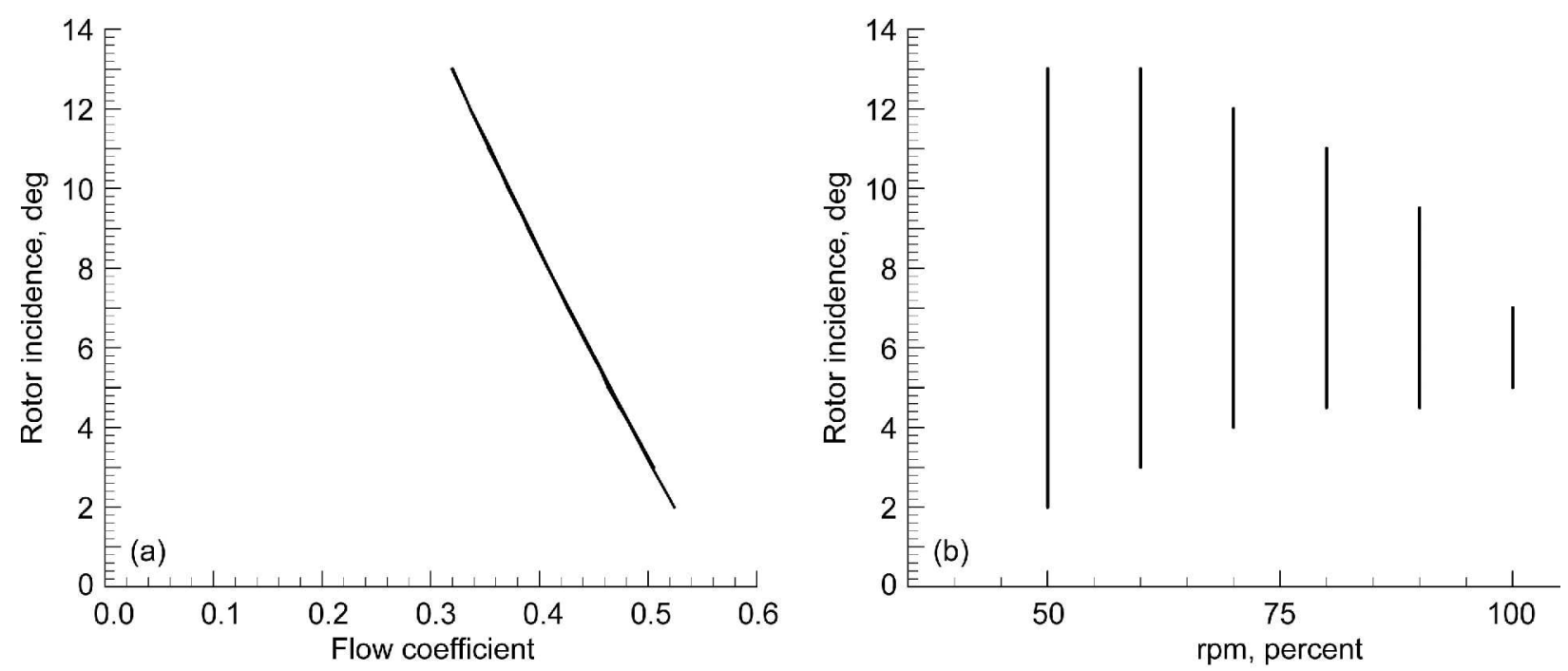

Figure 4.-(a) Variation of Stage 37 flow coefficient versus incidence. (b) Range of rotor incidence versus percent of design speed.
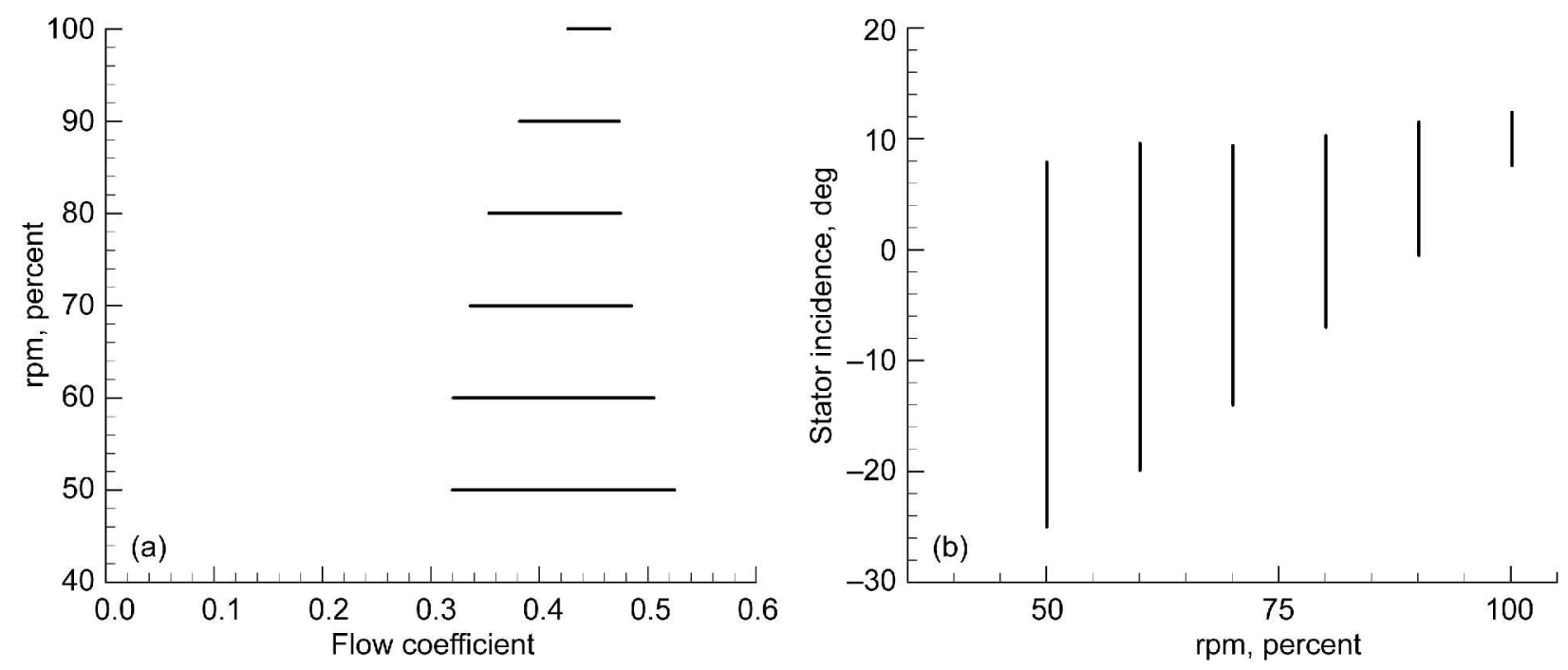

Figure 5.-(a) Flow coefficient variation with rotor speed. (b) Variation of stator incidence versus percent of design speed.

the rotor is completely transonic from tip to hub and the range of rotor incidence variation is only $2^{\circ}$, ranging from $5^{\circ}$ at choke to $7^{\circ}$ at surge. At the lower speeds the tip relative Mach number is reduced and ultimately becomes completely subsonic at 70 percent speed and lower. On the 50 percent speed line the incidence range is $11^{\circ}\left(2^{\circ}\right.$ at choke to $13^{\circ}$ at surge). The variation of flow coefficient as a function of corrected speed is shown in Figure 5(a). As expected the flow coefficient range from choke to surge is also dependent on the corrected speed, with the greatest range at low speeds and the narrowest range at the higher speeds. The design point output listing of the mean line code (COMDES version 11) is listed in Appendix B.

The stator leading edge metal angle is $42^{\circ}$ from the axial direction and remains fixed at all speeds. The range of incidence angles at the stator leading edge was analyzed and is summarized in Figure 5(b). The stator incidence angle near surge varies from $8^{\circ}$ on the 50 percent speed line to nearly $12^{\circ}$ on the 100 percent speed line. The stator incidence at choke varies from $7.6^{\circ}$ at 100 percent speed to $-25^{\circ}$ on the 50 percent speed line. 

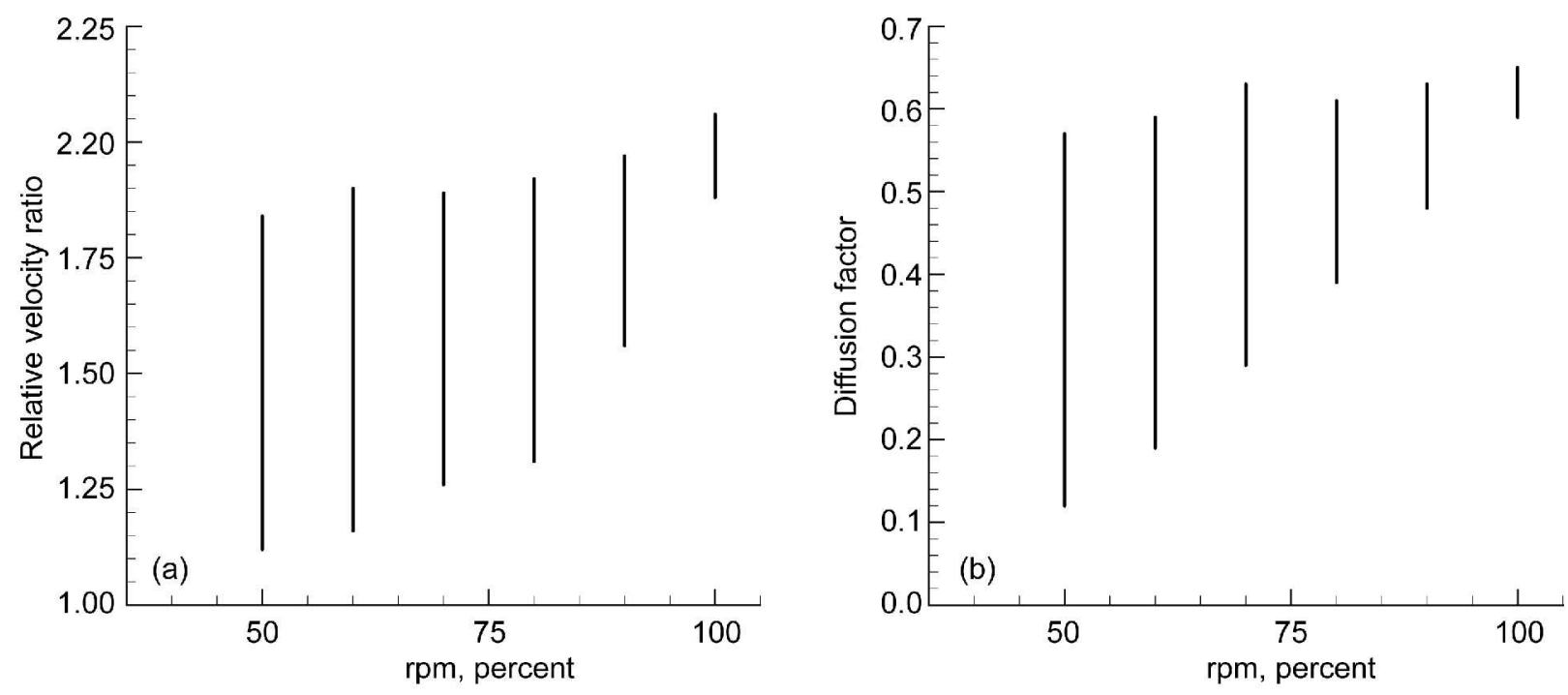

Figure 6.-Stage 37 Rotor relative velocity ratio (a) and diffusion factor (b) variation with speed.

TABLE 2.-DIFFUSION FACTOR, RELATIVE VELOCITY RATIO AND INCIDENCE NEAR SURGE FOR NASA STAGE 37

\begin{tabular}{|c|c|c|c|c|}
\hline $\begin{array}{c}\text { rpm, } \\
\text { percent }\end{array}$ & $\begin{array}{c}\text { Rotor diffusion } \\
\text { factor }\end{array}$ & $\begin{array}{c}\text { Rotor relative } \\
\text { velocity ratio }\end{array}$ & $\begin{array}{c}\text { Rotor } \\
\text { incidence }\end{array}$ & $\begin{array}{c}\text { Stator } \\
\text { incidence }\end{array}$ \\
\hline 100 & 0.65 & 2.06 & 7.0 & 12.4 \\
\hline 90 & 0.63 & 1.97 & 9.5 & 11.5 \\
\hline 80 & 0.61 & 1.92 & 11.0 & 10.3 \\
\hline 70 & 0.63 & 1.89 & 12.0 & 9.4 \\
\hline 60 & 0.59 & 1.90 & 13.0 & 9.6 \\
\hline 50 & 0.57 & 1.84 & 13.0 & 7.9 \\
\hline
\end{tabular}

The relative velocity ratio through the rotor from the inlet tip to the exit mean value is a measure of the amount of diffusion through the rotor and thus can be correlated to the onset of separation. The rotor relative velocity ratio that is calculated in the code is based on the relative velocity at the inlet tip and the exit mean line relative velocity. This parameter may be used as a first order guide to determine the compressor surge point. Based on analysis with the mean line code, the relative velocity ratio at surge for this rotor reaches a maximum of value 2.05 on the 100 percent speed line, while at lower speeds the value at surge is near 1.80 . However, since the mean line model along the 100 percent speed line shows slightly higher pressure ratio and flow than the data, the calculations on the 100 percent speed line may not be reliable. The variation of relative velocity ratio through the Stage 37 rotor as a function of speed is shown in Figure 6(a). Another key parameter that can be used to determine the stall or surge is the rotor diffusion factor. Based on the mean line flow analysis of Stage 37 test data, the diffusion factor at surge on the 100 percent speed line is 0.63 , while at the lower speeds the diffusion factor at surge is 0.58 . The rotor diffusion factor as a function of rotor speed in Figure 6(b) reaches a value of 0.63 at 100 percent speed.

Analysis with the mean line methodology has yielded the values for key parameters at surge along each speed line. Table 2 summarizes the values of rotor diffusion factor, relative velocity ratio and incidence, as well as the stator incidence, at the flow where surge was encountered at each speed line for NASA Stage 37.

Since the model slightly over-predicted the pressure rise and mass flow on the 100 percent speed line, it is likely that the rotor diffusion factor of 0.65 and relative velocity ratio of 2.06 that the model calculated are not an accurate estimate of their real values at surge. On the 90 through 50 percent speed lines the values of rotor diffusion factor and relative velocity ratio at surge are reasonably constant near 0.60 and 1.90 , respectively. As there is good agreement between the test data and the mean line model along these speed lines, the values of diffusion factor and relative velocity ratio at surge are considered to be accurate. The rotor and stator incidences at surge vary on each speed line. 


\section{NASA 74-A Three Stage Axial Compressor}

The three stage NASA 74-A (Ref. 5), axial compressor was built and tested in the 1980s and is illustrated in Figure 7. The design details about this variable geometry multistage compressor are described in Reference 5. This compressor was selected in order to validate the capability of the mean line code methodology for generating a performance map for a multistage compressor with variable geometry, and to improve understanding about matching of multistage compressors at part-speed conditions.

The 74-A compressor had a variable inlet guide vane (IGV) as well as variable stators in stages 1,2 , and 3 as illustrated in Figure 8. There were three builds of the 74-A compressor, with each build having a different variable geometry schedule. The current flow analysis of the 74-A compressor is focused on the configuration, which had an optimized variable geometry schedule to achieve the best aerodynamic efficiency and stage matching at all speed lines. The geometry schedule was optimized on the test stand at each speed line.

As illustrated in Figure 8, the sign convention utilized for the variable geometry reset angles is as follows: positive reset angle is in the direction of rotation, and negative reset angle indicating against the direction of rotation. This compressor was simulated with the mean line code at all tested rotational speeds and the analysis results were compared to the test data as shown in Figure 9. The input slip factor for the mean line analysis was 0.96 for all three rotors as this produced the best fit with the pressure ratio versus speed and flow test data. The design point efficiency at the tip, mean and hub for the three rotors were obtained from the original design report and input into the mean line code as follows: rotor 1: 78.1, 88.3, and 93.4 percent; rotor 2: 83.5, 90.0, and 92.5 percent; rotor 3: 86.9, 91.1, and 92.2 percent. The rotor efficiencies were varied at off-design levels of incidence by the relation in Equation (31). The stator loss coefficient utilized in the analysis was 6 percent as defined by Equation (27). The aerodynamic blockages at the rotor inlet and exit were 2 and 5 percent. The slip factor, stator loss and aerodynamic blockages were fixed at off design. Note that while these assumptions are known to be not what actually occurs in the compressor, they are considered to be reasonable in order to approximate the values

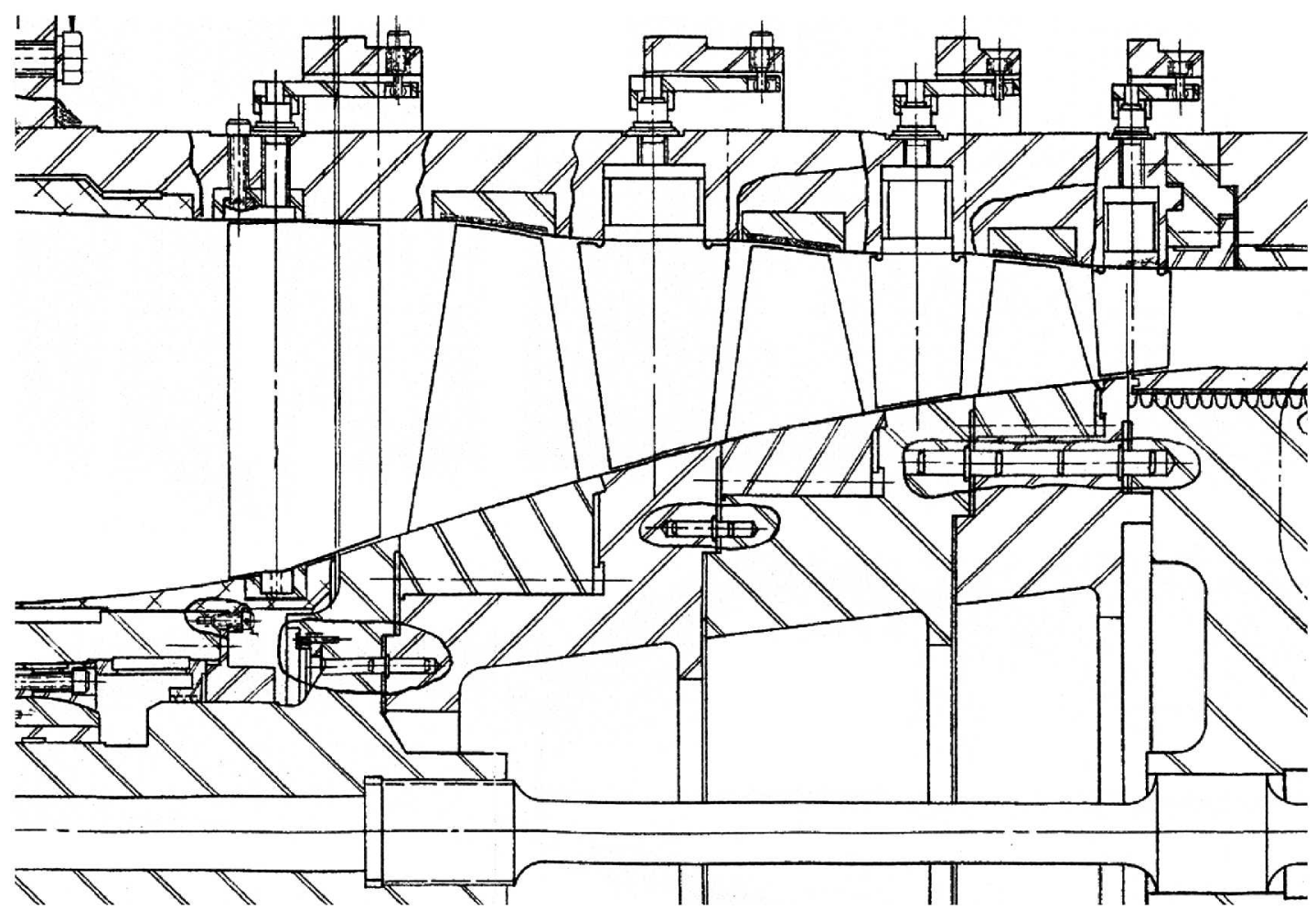

Figure 7.-NASA 74-A three stage axial compressor with variable IGV and variable stators 1, 2, and 3. 


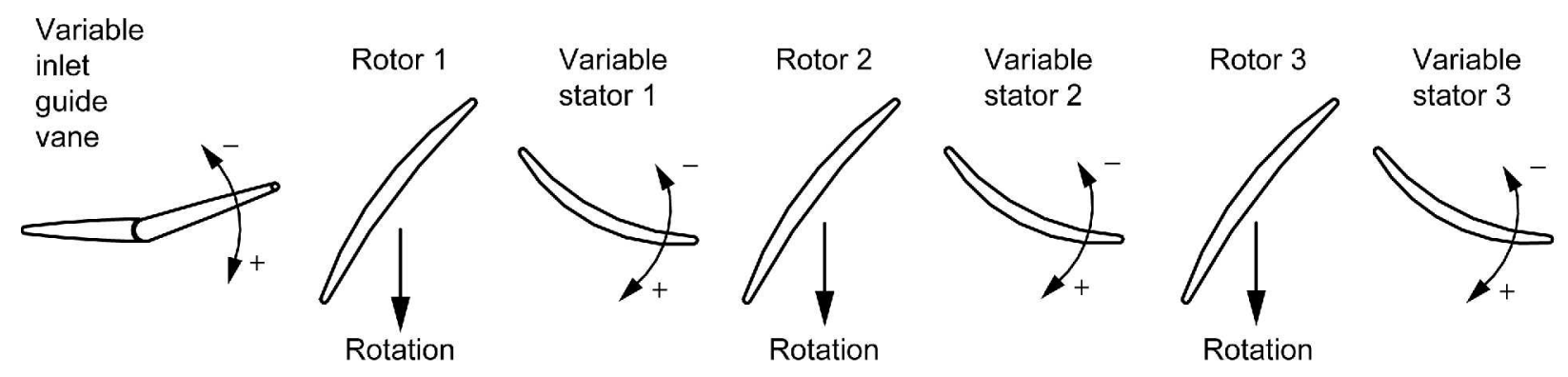

Figure 8.-The variable geometry reset angle sign convention used in the flow analysis of the 74-A compressor.

of aerodynamic parameters within the compressor. There is quite good agreement at all speeds in the pressure ratio versus flow and speed map of Figure 9(a), but less agreement with the efficiency shown in Figure 9(b). The optimized variable geometry schedule obtained by testing is included as a table insert in Figure 9. The 74-A compressor test data showed an overall peak adiabatic efficiency near 88 percent or above on several speed lines, while the mean line code shows 85 percent as the peak efficiency. It is possible that the rotors were more efficient than the values listed in the design report and the stators had less loss than the values listed in the design report. The optimized variable geometry reset schedule obtained by testing is included as a table insert in Figure 9. Even the build of 74-A referred to as "optimized geometry" required extensive fine tuning on the test stand at the 100 percent speed line, by adjustments of the variable geometry inlet guide vane and variable stators, as shown in the insert of Figure 9(b).

Considering this, the 88 percent peak efficiency that was obtained on test seems high, as the reset angles required to aerodynamically match the compressor stages meant that losses must have been incurred in the process of matching them. The efficiency achieved on test also seems high considering that the 74-A rotors and stators were multiple circular arc blade shapes, which typically provide limited control of span wise and stream wise work distribution during the design process.

The comparison between the mean line model and the data was taken to be adequate in order to compare the effects of the variable geometry reset angles. The results from the code were analyzed to better understand how rotor incidence and diffusion factor, influence the aerodynamic matching of the three stages.

The mean line analysis provides an understanding of the incidences that were encountered by the rotors and stators in build 3 featuring the variable geometry schedule that was optimized during testing. Analysis of the code output results shows the range of rotor incidences for each of the three stages from choke to surge as a function of percent mechanical rotational speed in Figure 10.

As illustrated in Figure 10, the range of incidence variation for each of the three rotors from choke to surge is from $4^{\circ}$ at the 100 percent speed line to $8^{\circ}$ at the lower speed lines. This range of rotor incidence variation is lower than the rotor incidence range of the previous single stage case (NASA Stage 37), especially at the lower speed lines. As shown in Figure 10(a), the first stage rotor experiences a continuously increasing incidence at reduced speeds. It is possible that the first rotor may be in stall at the 50 and 60 percent speed lines as the incidence there exceeds $13^{\circ}$ (the level of incidence where surge was encountered in Stage 37), and reaches a value of $17^{\circ}$ at the surge line. In addition, the test data on the compressor map of Figure 9(a) shows a flat pressure rise characteristic near surge on the 60 and the 50 percent speed lines that may be caused partially by flow separation in the first rotor even before compressor surge is encountered. 

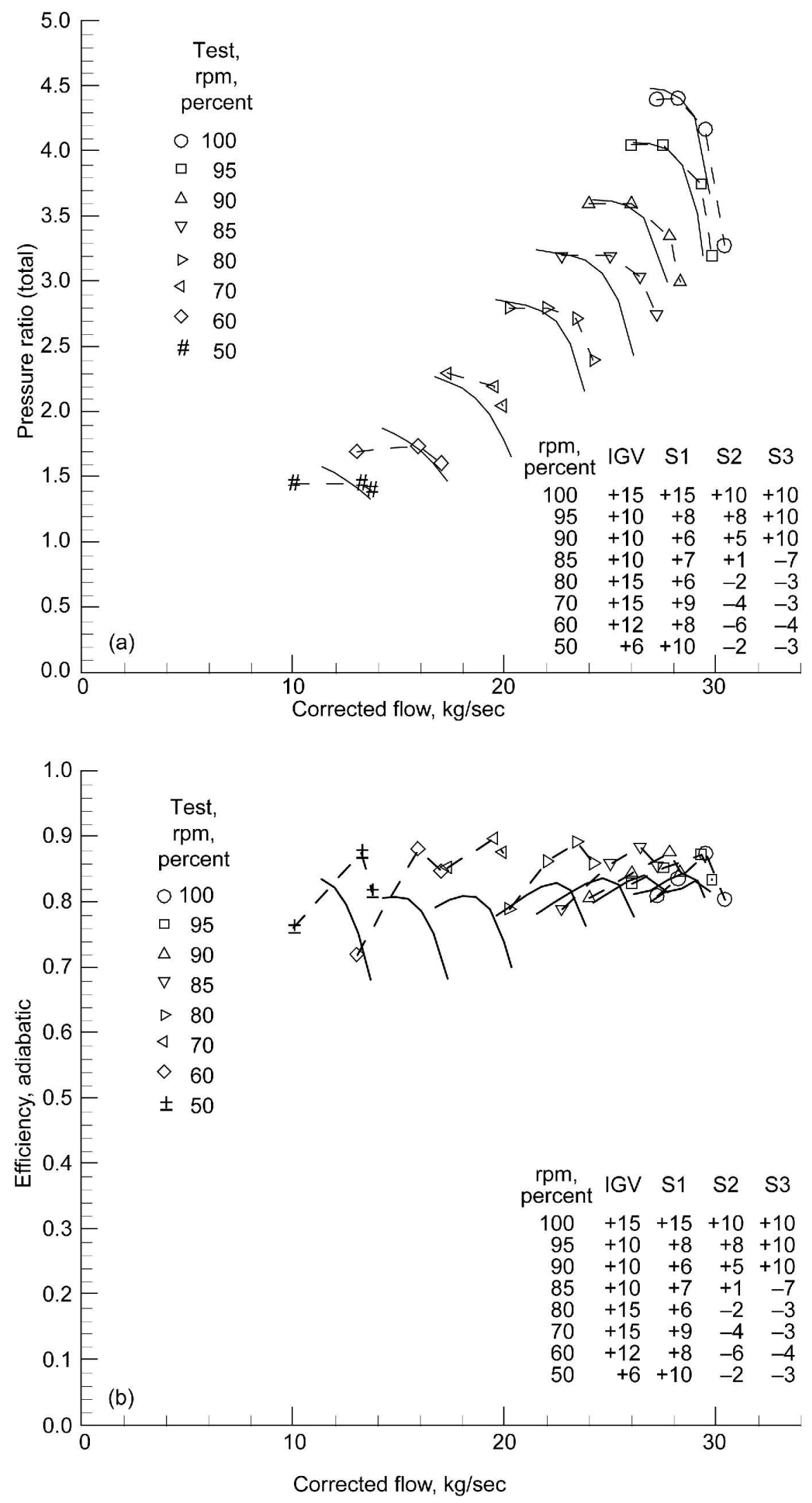

Figure 9.-NASA 74-A three stage compressor (Build 3) test (symbols) compared to mean line model, with variable geometry reset schedule. 

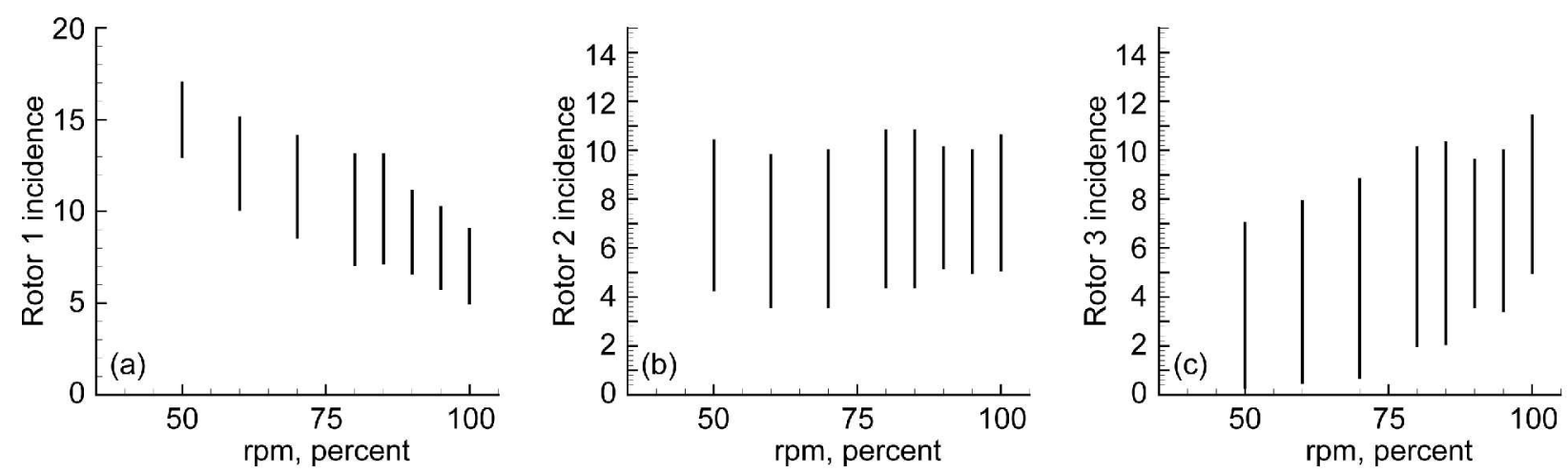

Figure 10.-Incidence range (degrees) versus speed of rotors 1 (a), 2 (b), and 3 (c) of the 74-A compressor.
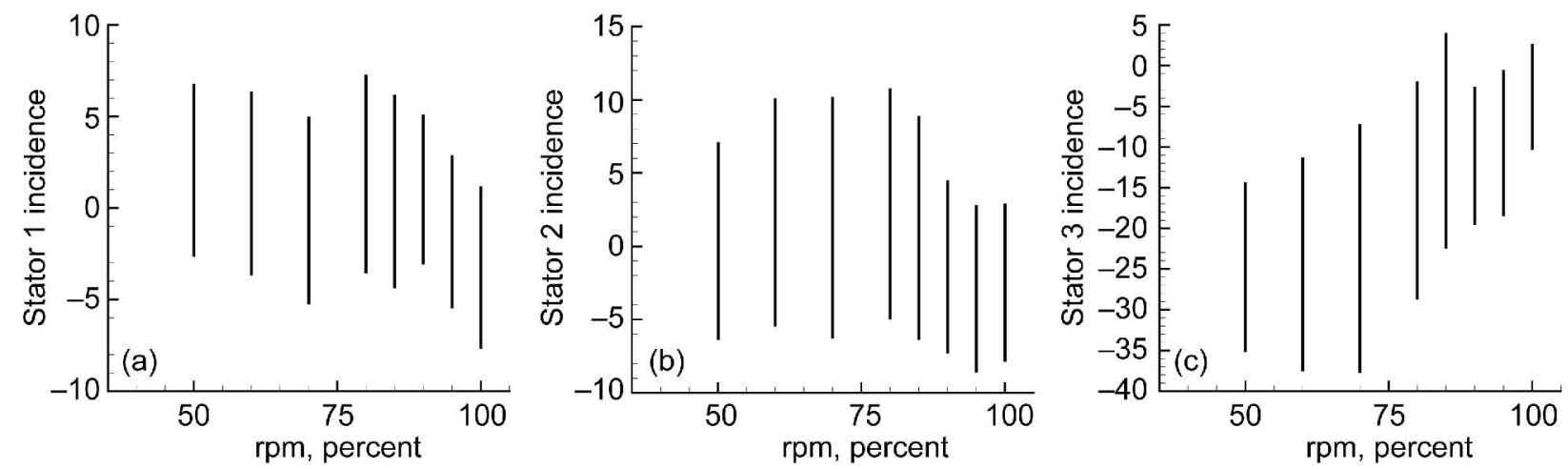

Figure 11.-Incidence variation (degrees) with speed for stators 1 (a), 2 (b), and 3 (c) of the 74-A compressor.

The rotor incidence angle variation is an aerodynamic parameter that may have a key role in aerodynamic matching of multistage compressors at design and at off-design operation. Consequently it can be important to consider rotor incidence when determining the variable geometry schedule required for matching multistage compressors. However, improved models beyond this mean line methodology are likely required in order to optimally match advanced highly loaded compressors featuring arbitrary blade shapes.

The variable geometry stators enable the alignment of the flow with the downstream rotor to achieve good rotor incidence and hence good stage matching. During the process of resetting the variable stator in order to improve the incidence on the rotor, the stator leading edge itself becomes subjected to incidence and additional losses. Note that these additional stator losses incurred due to incidence were not modeled, but rather were lumped into the single incidence loss model of Equation (31). Based on the mean line analysis of 74-A, it appears that the trend of stator incidence variations seem to track the variation in rotor incidence, making the lumped incidence loss assumption a reasonable approximation. An analysis of the stator leading edge incidence was done with the mean line methodology at all operating points on the map to determine the range of incidence angle variation at each speed line. The range of incidence angle variation from choke to surge of stators 1,2 , and 3 as a function of percent shaft mechanical speed are shown in Figure 11.

As shown in Figure 11(a) the incidence range of stator 1 is well balanced from $7^{\circ}$ to $-8^{\circ}$ at all speed lines. Stator 2 has an incidence variation of $11^{\circ}$ to $-9^{\circ}$ from choke to surge at all speed lines as shown in Figure 11(b). However, the range of incidence for stator 3 as shown in Figure 11(c) is from $5^{\circ}$ to $-37^{\circ}$ and appears to be not optimally set for a well balanced range of incidence, particularly at speeds below 100 percent. As there was no rotor 4 following stator 3, its aerodynamic function was limited primarily to efficient pressure recovery of the exit flow from rotor 3 , and did not have the additional function of being a guide vane for a downstream rotor. It would seem that the pressure recovery of stator 3 might have been 

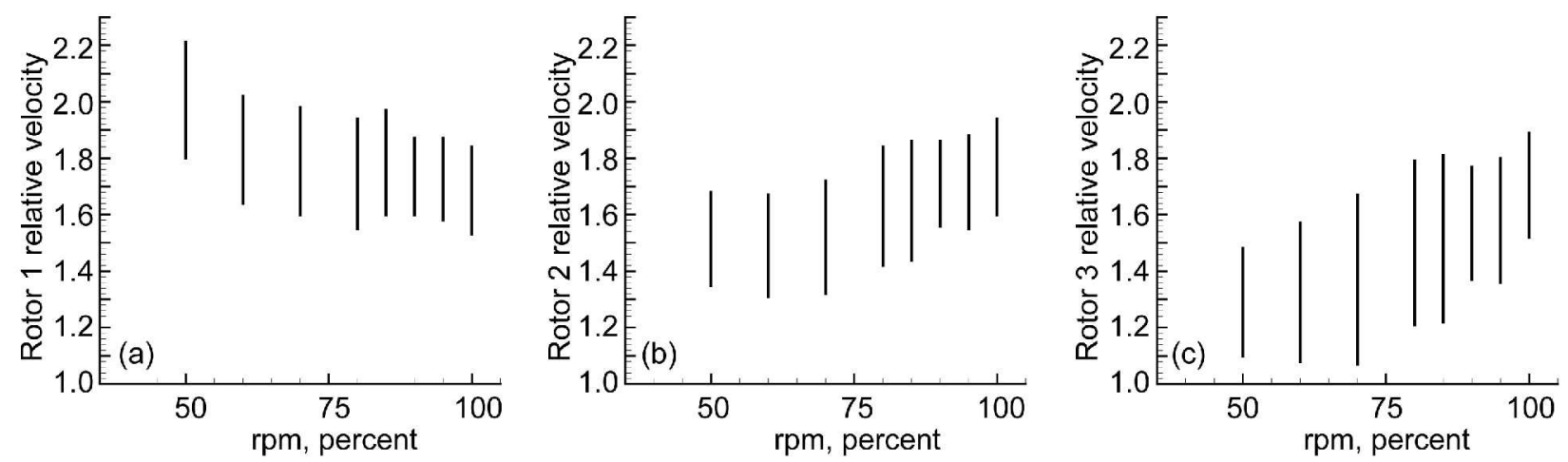

Figure 12.--Relative velocity ratio versus speed for rotors 1 (a), 2 (b), and 3 (c) of the 74-A compressor.
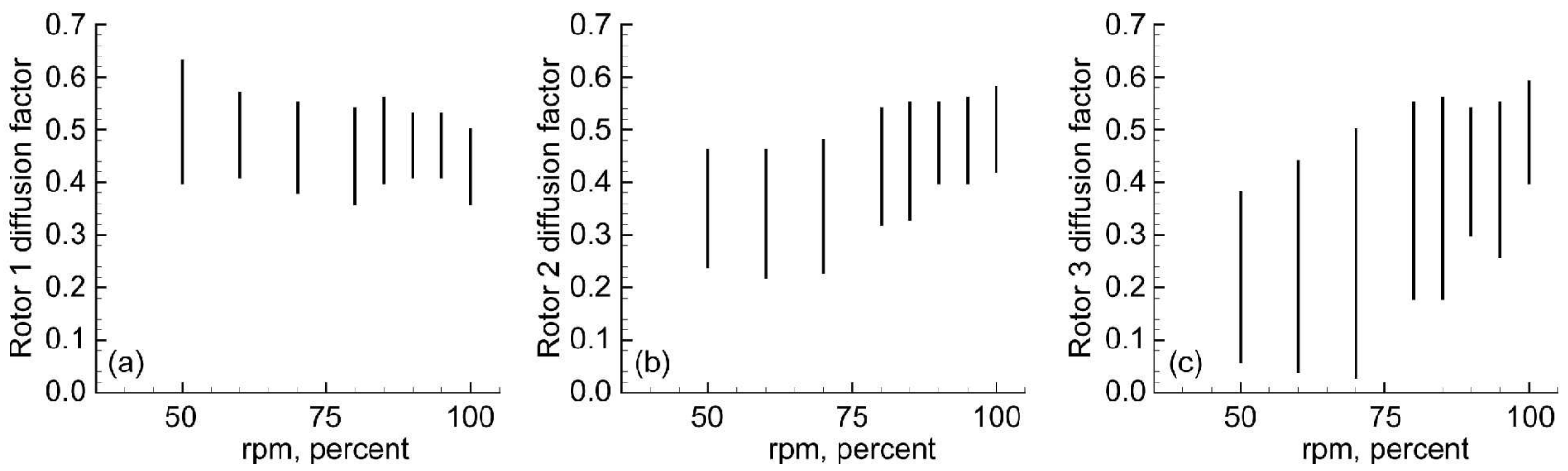

Figure 13.-Diffusion factor range versus speed for rotors 1 (a), 2 (b), and 3 (c) of the 74-A compressor.

improved if it had been reset to minimize incidence at the lower speed lines. However, it should be noted that at lower speeds the volume flow through the last stage is typically relatively high and that stator 3 is likely to be the first to choke thus limiting the amount of mass flow that could pass through the entire compressor. Further analysis of this compressor with a computational fluid dynamic code could improve understanding of why the variable geometry schedule that was selected provided the best performance at all speed lines, and in particular why the reset schedule of stator 3 was set at such high values of incidence especially at the lower speed lines.

Figure 12(a) shows the relative velocity ratio in rotor 1 exceeded the values reached in rotors 2 and 3 and actually reaches a value of 2.2 before the compressor surges on the 50 percent speed line, indicating the possibility that rotor 1 may have been in stall for part of the $80,70,60$, and 50 percent speed lines. Figure 13 shows the range of diffusion factors of rotors 1, 2, and 3 on all speed lines. Figure 13(b) and (c) illustrate that rotors 2 and 3 reach their highest values of diffusion factor of 0.59 at the 100 percent speed line, a value which is higher than the diffusion factor of rotor 1 at that speed. This indicates the possibility that rotor 2 or rotor 3 may have been responsible for initiating surge at the 100 percent speed line.

Analysis of the NASA 74-A compressor with the mean line methodology has yielded the values for rotor diffusion factor, relative velocity ratio and incidence at surge. Table 3 summarizes these values near the flow where surge was encountered at each speed line during testing. The design point output listing of the 74-A compressor analysis with the mean line code is listed in Appendix C. 
TABLE 3.-DIFFUSION FACTOR, RELATIVE VELOCITY RATIO AND INCIDENCE NEAR SURGE FOR THE NASA 74-A COMPRESSOR

\begin{tabular}{|c|c|c|c|c|c|c|c|c|c|c|c|c|}
\hline & \multicolumn{4}{|c|}{ STAGE 1} & \multicolumn{4}{|c|}{ STAGE 2} & \multicolumn{4}{|c|}{ STAGE 3} \\
\hline $\begin{array}{c}\text { rpm, } \\
\text { percent }\end{array}$ & $\begin{array}{c}\text { Rotor } 1 \\
\text { DF }\end{array}$ & $\begin{array}{l}\text { Rotor } 1 \\
\text { W1/W2 }\end{array}$ & $\begin{array}{c}\text { Rotor } 1 \\
\text { Inc }\end{array}$ & $\begin{array}{c}\text { Stator } 1 \\
\text { Inc }\end{array}$ & $\begin{array}{c}\text { Rotor } 2 \\
\text { DF }\end{array}$ & $\begin{array}{l}\text { Rotor } 2 \\
\text { W1/W2 }\end{array}$ & $\begin{array}{c}\text { Rotor } 2 \\
\text { Inc }\end{array}$ & $\begin{array}{c}\text { Stator } 2 \\
\text { Inc }\end{array}$ & $\begin{array}{c}\text { Rotor } 3 \\
\text { DF }\end{array}$ & $\begin{array}{l}\text { Rotor } 3 \\
\text { W1/W2 }\end{array}$ & $\begin{array}{c}\text { Rotor } 3 \\
\text { Inc }\end{array}$ & $\begin{array}{c}\text { Stator } 3 \\
\text { Inc }\end{array}$ \\
\hline 100 & 0.50 & 1.84 & 9.0 & 1.1 & 0.58 & 1.94 & 10.6 & 2.8 & 0.59 & 1.89 & 11.4 & 2.5 \\
\hline 95 & 0.53 & 1.87 & 10.2 & 2.8 & 0.56 & 1.88 & 10.0 & 2.7 & 0.55 & 1.80 & 10.0 & -0.7 \\
\hline 90 & 0.53 & 1.81 & 11.1 & 5.0 & 0.55 & 1.86 & 10.1 & 4.4 & 0.54 & 1.77 & 9.6 & -2.8 \\
\hline 85 & 0.56 & 1.97 & 13.1 & 6.1 & 0.55 & 1.86 & 10.8 & 8.8 & 0.56 & 1.81 & 10.3 & 3.8 \\
\hline 80 & 0.54 & 1.94 & 13.1 & 7.2 & 0.54 & 1.84 & 10.8 & 10.7 & 0.55 & 1.79 & 10.1 & -2.1 \\
\hline 70 & 0.55 & 1.98 & 14.1 & 4.9 & 0.48 & 1.72 & 10.0 & 10.1 & 0.50 & 1.67 & 8.8 & -7.4 \\
\hline 60 & 0.57 & 2.02 & 15.1 & 6.3 & 0.46 & 1.67 & 9.8 & 10.0 & 0.44 & 1.57 & 7.9 & -11.5 \\
\hline 50 & 0.63 & 2.21 & 17.0 & 6.7 & 0.46 & 1.68 & 10.4 & 7.0 & 0.38 & 1.48 & 7.0 & -14.5 \\
\hline
\end{tabular}

Analysis of the values in Table 3 indicates the stage which might have stalled first and therefore may have been the stage responsible for the onset of surge on each speed line. From the analysis it appears that on the 100 and 95 percent speed lines, stages 2 and 3 are the first ones to encounter stall as they have the highest values of rotor diffusion factor $(0.59,0.58)$, relative velocity ratio $(1.89,1.94)$ and incidence $(11.4,10.6)$. At the 95 percent speed line, stage 2 may have stalled first, as it has the highest values of rotor diffusion factor $(0.56)$ and relative velocity ratio (1.88). On the 90 percent speed line it appears that the second stage initiated stall, as it has the highest values of rotor diffusion factor $(0.55)$ and relative velocity ratio (1.86). On the 85 and 80 percent speed lines the diffusion factors are virtually equal in all three rotors. On the 70 percent speed line and below it appears that the first stage was the first to stall, as the values of rotor diffusion factor (0.56), relative velocity ratio (1.97) and rotor incidence (13.1) are higher than in stages 2 and 3 . On the 50 and 60 percent speed lines near surge of Figure 9(a) the mean line model shows a constantly increasing pressure ratio characteristic, while the test data shows a relatively flat pressure rise for nearly half of the speed lines. As there is not good agreement near surge on those two speed lines, it is likely that the rotor 1 diffusion factor of 0.63 and relative velocity ratio of 2.21 that the model calculated on the 50 percent speed line are not an accurate estimate of their real values at surge. Further development of the mean line methodology is planned to improve the accuracy even under conditions where one of the compressor blade rows may be in stall, but the compressor is not yet in surge. In addition, further analysis of the 74-A compressor is planned with computational flow simulation codes at select speed and flow conditions on the map to improve understanding of aerodynamic stage matching.

\section{NASA 76-B Three Stage Axial Compressor}

The mean line compressor code has been used as a quick tool for aerodynamically matching the stages within this multistage compressor at off-design (part-speed) operating conditions by means of variable geometry and inter-stage bleeds. This capability can be used as an initial estimate of the variable geometry schedule required for safe operation between choke and surge at part-speed operating conditions such as during initial startup. The NASA 76-B (Ref. 6), compressor is a three stage research compressor designed and built in the $1980 \mathrm{~s}$ is currently being taken out of storage and is being refurbished and readied for testing for the first time. The primary purpose of this test will be to verify the integrity of the two bearing running gear under full load, as this facility will be used in the future for subsequent advanced multistage compressor testing. The secondary purpose of the test will be to get aerodynamic data on the 76-B compressor, as it has not been tested in the past. Similar to the previous 74-A unit, this compressor was also designed with the Crouse (Ref. 7), axial compressor design program which can generate simple blade shapes comprised of multiple circular arc shapes. While the design point performance and the variable geometry reset angles at the 100 percent speed line are known from the original design simulation, the off-design performance has not been estimated in the past. To avoid compressor surge during startup, an accurate estimate of the variable geometry schedule for safe operation had to be determined. The cross section for the 76-B compressor is shown in Figure 14. 


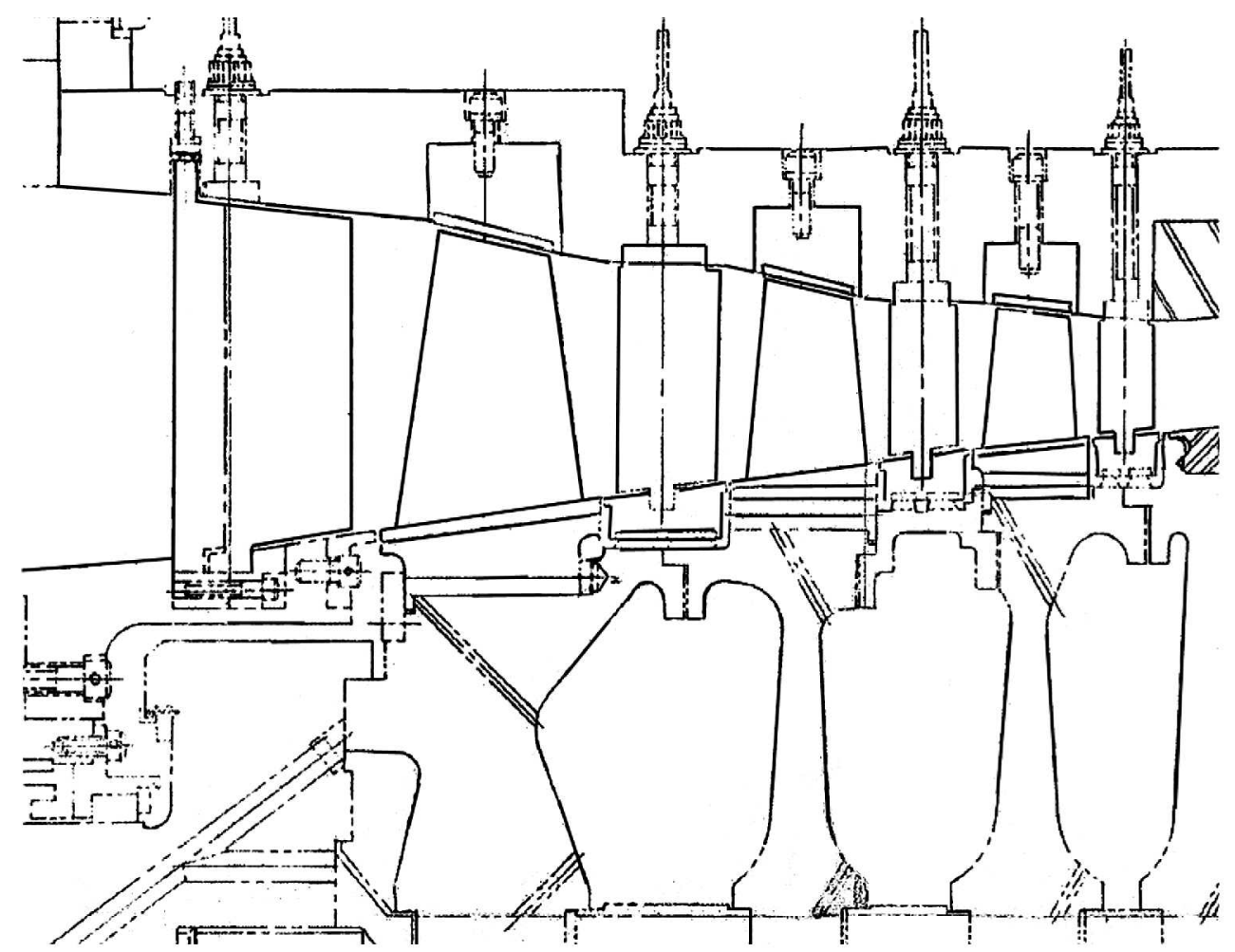

Figure 14.-NASA 76-B three stage axial compressor with variable IGV and variable stators 1, 2, and 3.

Testing of the 76-B compressor is tentatively scheduled for the summer of 2009 at the NASA Glenn Research Center Engine Research Building test cell W7. Whether or not testing will be done will depend on results from an ongoing inspection of the compressor hardware. As in the previous case, this highly loaded compressor also has variable geometry inlet guide vanes and variable stators 1,2, and 3 as illustrated in Figure 8 . There is a need to analytically determine the variable geometry and inter-stage bleed schedule that will provide a safe startup operating line so that the initial mechanical shakedown tests can proceed free of compressor surge. The mean line flow code was used to predict the performance map for this compressor and to determine the variable geometry schedule that would provide a recommended operating line for safe startup. This methodology was selected for the initial analysis over a higher fidelity computational fluid dynamics analysis (CFD) technique, as it would have been computationally expensive to iteratively determine the variable geometry schedule with CFD. However, it is planned to verify the reset schedule determined by the mean line analysis with CFD prior to testing.

A multistage compressor map was created based on the one-dimensional flow methodology. Rotor incidence was assumed to be a key parameter for determining the reset angles for the variable geometry inlet guide vanes and variable stators for matching of multistage compressors at all operating speeds. As such, the variable geometry schedule was determined iteratively using the mean line code by placing priority onto the range of incidence of rotors 1,2 , and 3 . As the rotor incidence at the peak efficiency used in the mean line model is $6^{\circ}$, the variable geometry inlet guide vanes and stators were reset manually to attempt to provide that level of incidence near the "backbone" of the compressor map. While the rotor incidence does vary extensively along a speed line, as has been observed on the previous case analyzed (NASA 74-A compressor), the goal of this effort was to minimize the variation in either direction from the $6^{\circ}$ rotor incidence. This was done concurrently while staying within the empirical stall limits $(0.60$ rotor diffusion factor and 1.90 relative velocity ratio) and the choke limit. The choke limit was determined by increasing the flow rate until the mean line code no longer converged. 
Varying the reset angles to control rotor incidence also influenced the levels of diffusion factor and relative velocity ratio. As the variable stators were in effect the guide vanes for the downstream rotor, they were reset in a manual iterative process until acceptable levels of incidence and diffusion factor were obtained on all three rotors. The goal was to control the level of diffusion factor through each rotor not to exceed a maximum value of 0.60 . Note that the surge line was determined to be where the diffusion factor reaches a value of 0.60 in any of the three rotors at a particular operating point. The resultant compressor characteristic pressure ratio and efficiency versus flow and speed map and the variable geometry reset schedule based on analysis with the mean line code is shown in Figure 15.

As can be seen in Figure 15(b), the levels of peak efficiency are reduced at the lower speed lines, due mainly to the large reset angles of the inlet guide vane. While the suggested variable geometry schedule is expected to provide a safe startup line free of compressor stall and surge, it may be at the cost of some efficiency, particularly at the reduced speed lines. Figure 15(b) can be compared to Figure 9(b), which has been optimized for efficiency on the test stand. It is likely that the variable geometry schedule of the 76-B compressor will also need to be fine tuned on the test stand to result in the optimum efficiency at all speed lines.

Note that the performance map for the 76-B compressor is a prediction based on the mean line methodology and the off-design models within the code, but the levels of rotor efficiency at the design point were input values obtained from the compressor design code originally used to design the 76-B compressor as follows: rotor 1: Tip: 78.1 percent, Mean: 88.3 percent, Hub: 93.4 percent; rotor 2: Tip: 83.5 percent, Mean: 94.0 percent, Hub: 92.5 percent; rotor 3: Tip: 86.9 percent, Mean: 91.1 percent, Hub: 92.2 percent. Stator losses used in the mean line analysis were 6 percent and slip factor was 0.945 or slightly lower than the 74-A machine to be conservative on pressure ratio prediction. Figure 16 shows the resulting rotor incidence variations which range from $3^{\circ}$ near choke to nearly $11^{\circ}$ near surge. The range of rotor incidence is in line with or less than that experienced in the 74-A machine.

As the variable stators were reset to control the incidence variation levels on the downstream rotors, the stators' leading edges also experience incidence variations as shown in Figure 17. At the higher speed lines, the level of stator 1 incidence is comparable to that of the 74-A compressor. On the lower speed lines, the maximum level of stator 1 incidence is higher than that experienced on the previous 74-A compressor. Stator 3 incidence has a much reduced range of variation in comparison to stator 3 in the 74-A compressor at part speed operation.

The range of relative velocity ratio on each speed line for the three rotors in the 76-B compressor are shown in Figure 18. The rotor 1 velocity ratio is lower than the levels experienced on the previous 74-A compressor rotor 1 . The maximum relative velocity ratio through rotors 2 and 3 are in line with or lower than those of 74-A.

The range of diffusion factors on each speed line for the three rotors of the 76-B compressor are shown in Figure 19. At a maximum value of 0.60 near surge, the rotor diffusion factors for the three rotors are also in line with and in some cases lower than the levels experienced on the previous 74-A compressor rotors, further increasing confidence in this test achieving the predicted surge line.

Based on the mean line analyses of the incidence range experienced by the rotors and stators, as well as the rotor maximum diffusion factor and relative velocity ratios at the surge line, it is expected that the 76-B compressor will meet or exceed the predicted flow range shown in Figure 15.

The recommended variable geometry schedule and safe start up line for the 76-B compressor are summarized in Table 4. The 76-B compressor mean line flow analysis at the design point is listed in Appendix D. 

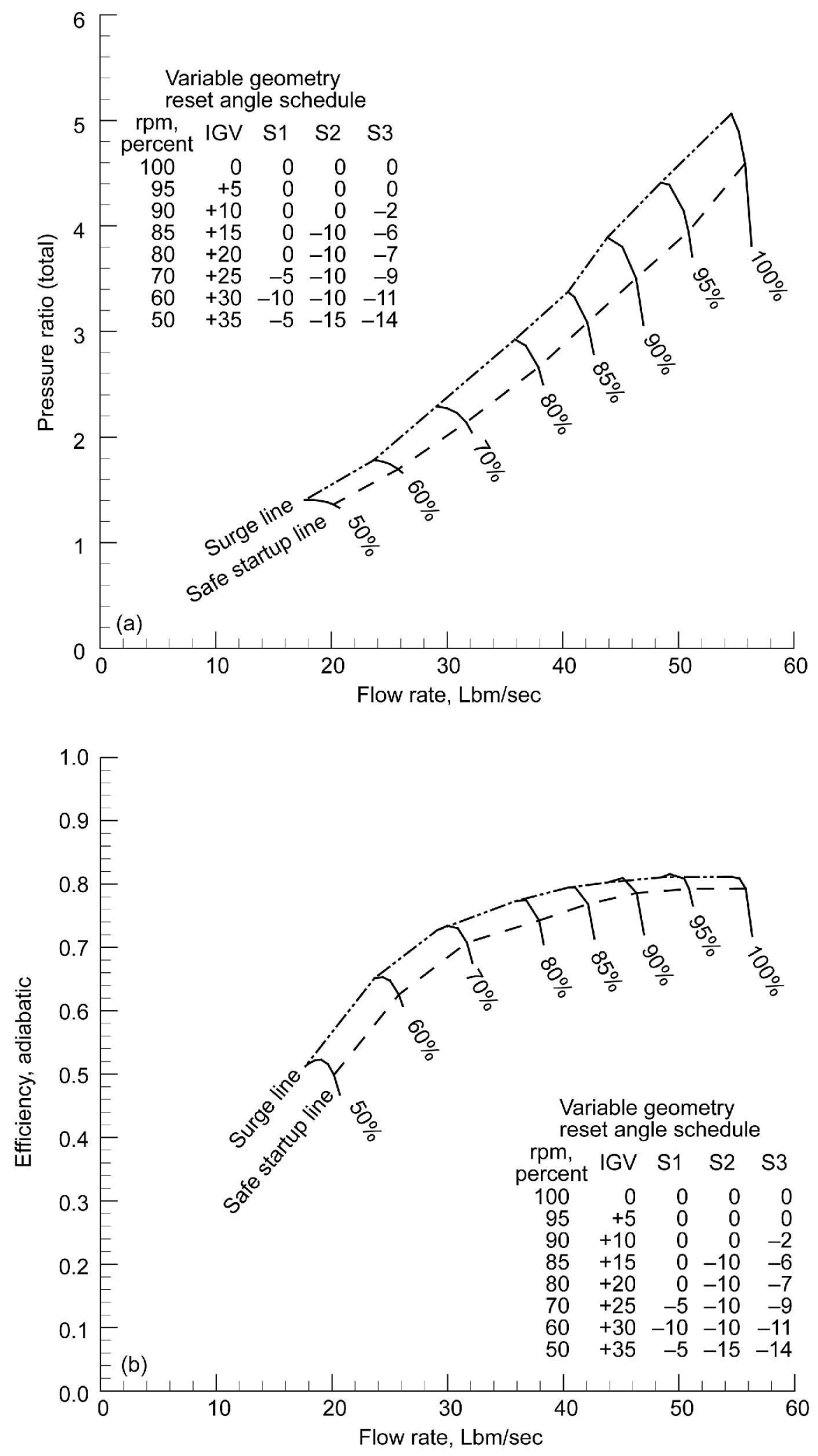

Figure 15.-NASA 76-B three stage axial compressor estimated pressure ratio (a) and efficiency (b) map with the variable geometry schedule that will provide a safe startup line for stall free part-speed operation. 

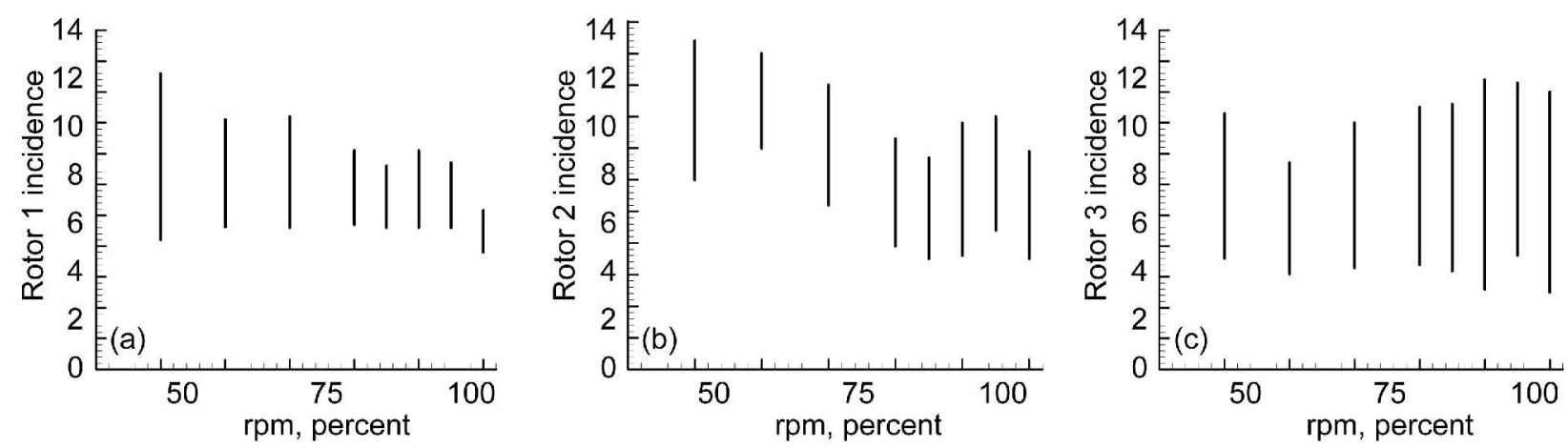

Figure 16.-Incidence range (degrees) versus speed of rotors 1 (a), 2 (b), and 3 (c) of the 76-B compressor.
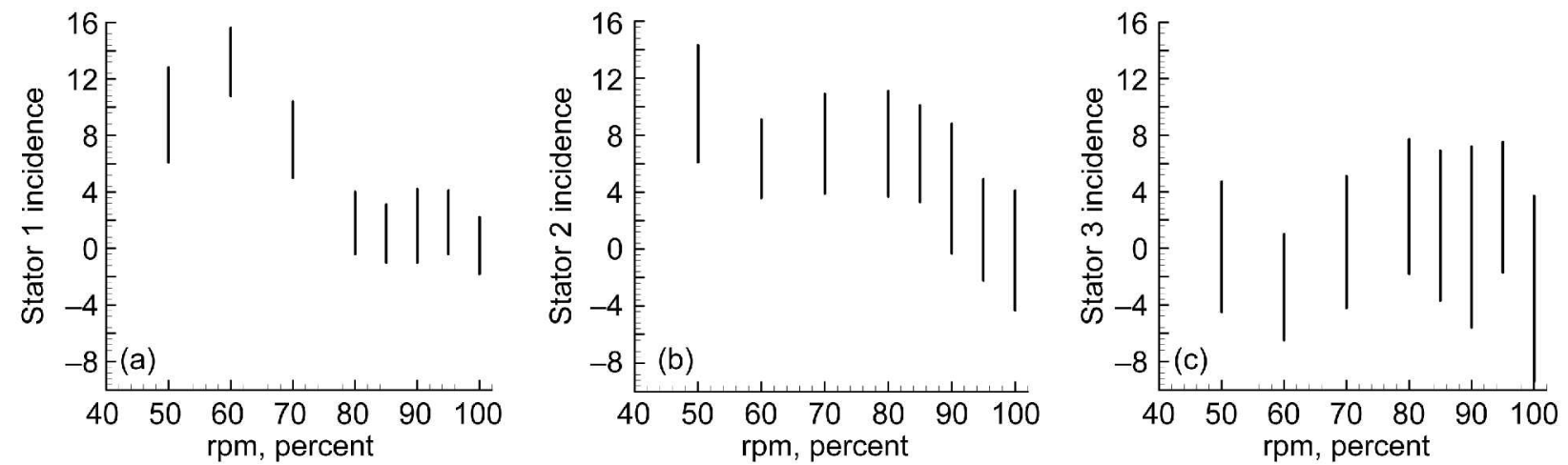

Figure 17.-Incidence variation (degrees) with speed for stators 1 (a), 2 (b), and 3 (c) of the 76-B compressor.
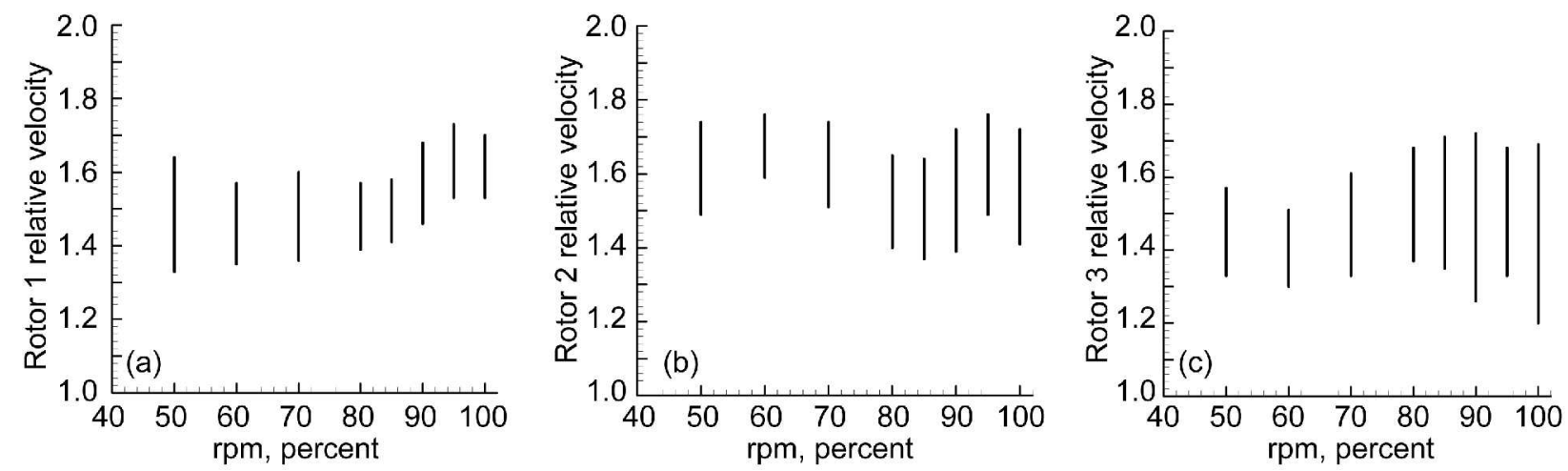

Figure 18.-Relative velocity ratio (degrees) range versus speed for rotors 1 (a), 2 (b), and 3 (c) of the 76-B compressor.
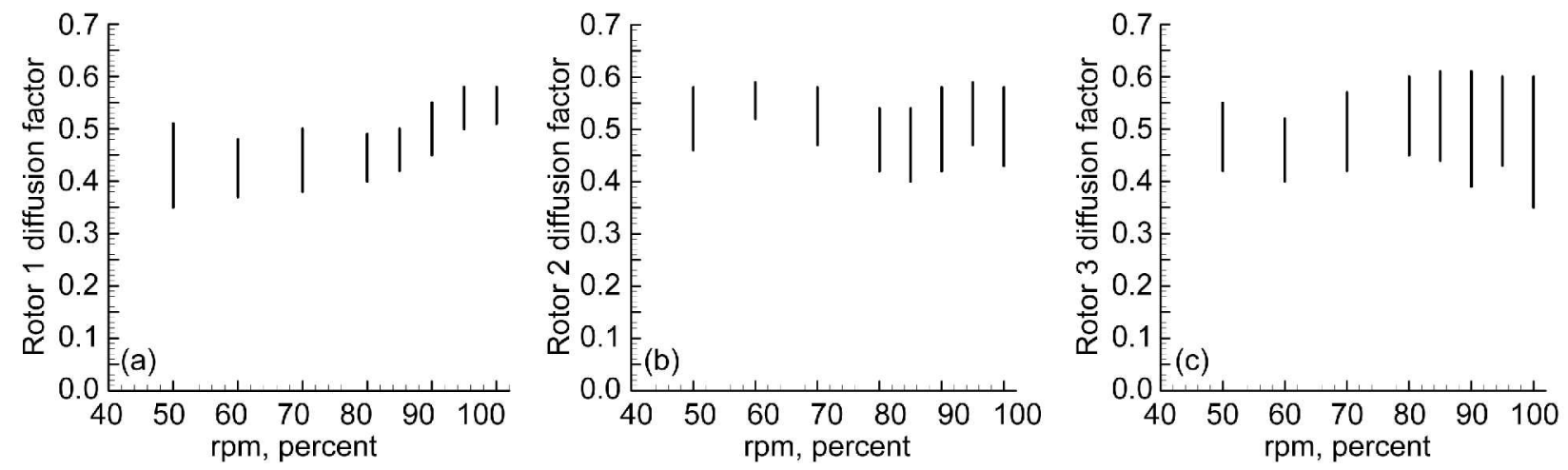

Figure 19.-Diffusion factor range versus speed for rotors 1 (a), 2 (b), and 3 (c) of the 76-B compressor. 
TABLE 4.-76-B THREE STAGE AXIAL COMPRESSOR STARTUP OPERATING LINE AND VARIABLE GEOMETRY SCHEDULE

\begin{tabular}{|c|c|c|c|c|c|c|}
\hline $\begin{array}{c}\text { Corrected speed, } \\
\text { percent }\end{array}$ & $\begin{array}{c}\text { Corrected mass flow } \\
\text { lbm/sec }\end{array}$ & $\begin{array}{c}\text { Pressure } \\
\text { ratio }\end{array}$ & $\begin{array}{c}\text { Inlet guide vane } \\
\text { reset angle }\end{array}$ & $\begin{array}{c}\text { Stator 1 reset } \\
\text { angle }\end{array}$ & $\begin{array}{c}\text { Stator 2 reset } \\
\text { angle }\end{array}$ & $\begin{array}{c}\text { Stator 3 reset } \\
\text { angle }\end{array}$ \\
\hline 100 & 55.77 & 4.59 & 0 & 0 & 0 & 0 \\
\hline 95 & 50.87 & 3.94 & 5 & 0 & 0 & -2 \\
\hline 90 & 46.34 & 3.50 & 10 & 0 & -5 & -5 \\
\hline 85 & 42.13 & 3.08 & 15 & 0 & -10 & -6 \\
\hline 80 & 37.90 & 2.66 & 20 & 0 & -10 & -7 \\
\hline 70 & 31.66 & 2.14 & 25 & -5 & -10 & -9 \\
\hline 60 & 25.78 & 1.69 & 30 & -10 & -10 & -11 \\
\hline 50 & 20.17 & 1.36 & 35 & -5 & -15 & -14 \\
\hline
\end{tabular}

\section{Conclusion}

The mean line flow analysis code COMDES has been written to provide a quick look at key aerodynamic parameters within single and multistage compressors. The design point rotor efficiency and stator loss coefficient are input into the code. The off-design performance is determined from models within the code based on the level of rotor incidence. Correlations to compressor surge have been estimated from the mean line analyses of NASA Stage 37 and NASA 74-A compressors, where rotor diffusion factor loading level near 0.60 and relative velocity ratio levels near 1.9 are experienced near surge in one or more of the compressor rotors along most of the tested speed lines. However, these values appear to be exceeded in rotor 1 of the 74-A unit on the lower speed lines, and perhaps on Stage 37 at the 100 percent speed line. Note that as the off-design correlations within the code are largely based on empirical models derived from Stage 37 and the 74-A compressors, it may not provide accurate representations of flow in modern compressors featuring arbitrary blade shapes. The mean line methodology has been used to provide some guidance as to how to run the NASA 76-B multistage compressor on the test stand by helping to guide the selection of variable geometry schedule which is expected to provide a wide range of operation. As the 76-B compressor consists of similar multiple circular arc blades as Stage 37 and the 74-A compressors, the performance prediction based on the mean line model is considered to be a reasonable approximation. Based on the mean line analysis, a startup schedule has been recommended for the 76-B compressor that is expected to provide a surge free start up line. However, it is planned that the variable geometry schedule will be fine tuned on the test stand to provide optimum efficiency at each speed line. More research is required to determine the relationship of incidence, diffusion factor and relative velocity ratio on each blade row to achieve optimum stage matching and overall efficiency with acceptable surge margin. The mean line methodology can also be used in the conceptual design process to size parameters such as number of stages and to estimate rotor inlet and exit blade angles to meet pressure ratio requirements. The mean line code is a research code currently under development and improved loss models are planned, including further validation of the code for modeling flow in centrifugal compressor stages. 


\section{Appendix A.-Governing Equations}

The rotor annular area is calculated from the hub and tip radii from the centerline by Equation (1). The aerodynamic blockage are specified as input parameters at the leading and trailing edges of the rotor in the mean line analysis, and is not varied at off-design operating conditions.

$$
A=\lambda \pi\left(R_{T}-R_{H}\right)\left[\left.\left(\left(R_{T}-R_{H}\right)^{2}+B^{2}\right)^{1 / 2}\right|^{1 / 2}\right.
$$

The static temperature is a function of the total temperature and the Mach number as shown in Equation (2).

$$
\frac{T_{t}}{T_{S}}=1+\frac{\gamma-1}{2} M^{2}
$$

The static pressure is a function of the total pressure and the Mach number as shown in Equation (3).

$$
\frac{P_{t}}{P_{S}}=\left(\frac{T_{t}}{T_{S}}\right)^{\frac{\gamma}{\gamma-1}}=\left(1+\frac{\gamma-1}{2} M^{2}\right)^{\frac{\gamma}{\gamma-1}}
$$

The volume flow rate into the rotor is determined by Equation (4) in terms of the mass flow rate, static pressure and temperature.

$$
Q=\frac{m T_{S} g_{C}}{P_{S}}
$$

The absolute velocity at the rotor inlet is shown in Equation (5) as a function of volume flow rate and inlet area.

$$
C=\frac{Q}{A}
$$

The speed of sound is determined from the static temperature and the gas properties as shown in Equation (6).

$$
a=\left(\gamma \mathfrak{R} T_{S} g_{C}\right)^{1 / 2}
$$

The Mach number is determined from the total velocity and the speed of sound as shown in Equation (7).

$$
M=C / a
$$

The meridional velocity is determined from the total velocity and the tangential component of absolute velocity as shown in Equation (8). 


$$
C_{M}=\left(C^{2}-C_{U}^{2}\right)^{1 / 2}
$$

The flow function of the rotor is defined by Equation (9) in terms of the axial component of velocity and the rotor peripheral speed.

$$
\Phi=\frac{C_{M}}{U_{T}}
$$

The tangential component of absolute velocity is determined from the absolute velocity and the inlet swirl angle as shown in Equation (10).

$$
C_{U}=C \operatorname{Tan}(\alpha)
$$

The relative flow angle is determined by Equation (11).

$$
\beta_{F}=\operatorname{Tan}^{-1}\left[\left.\frac{U-C_{U}}{C}\right|_{]}\right.
$$

The rotor incidence angle is defined as the difference between the relative flow angle and the blade angle at the rotor leading edge just upstream of the blade by Equation (12).

$$
i_{R}=\beta_{F}-\beta_{B}
$$

The relative velocity at the rotor leading edge is determined by Equation (13).

$$
W=C / \operatorname{Cos}\left(\beta_{F}\right)
$$

The rotor total-to-total adiabatic efficiency is defined by Equation (14).

$$
\eta=\frac{\left(\frac{P_{t 2}}{P_{t 1}}\right)^{\gamma-1 / \gamma}-1}{\frac{T_{t 2}}{T_{t 1}}-1}
$$

The enthalpy rise is calculated in terms of temperature rise across the rotor by Equation (15) and the Euler Equation (16) which is based on the change in tangential velocity from inlet to exit.

$$
\begin{gathered}
\Delta H=J c_{P} g_{C}\left(T_{t 2}-T_{t 1}\right) \\
\Delta H=U_{2} C_{U 2}-U_{1} C_{U 1}
\end{gathered}
$$

The meridional component of velocity is determined from the density, mass flow rate and area as shown in Equation (17). 


$$
C_{M 2}=\frac{m R T_{S 2}}{P_{S 2} A_{2}}
$$

The relative velocity at the rotor exit is determined from Equation (18).

$$
W_{2}=\left[\left(U_{2}-C_{U 2}\right)^{2}+C_{M 2}^{2}\right]^{1 / 2}
$$

The absolute flow angle at the rotor exit is determined from the relation shown in Equation (19).

$$
\alpha_{2}=\operatorname{Tan}^{-1}\left(\frac{C_{U 2}}{C_{M 2}}\right)
$$

The absolute velocity at the rotor exit is determined from Equation (20).

$$
C_{2}=\left(C_{U 2}^{2}+C_{M 2}^{2}\right)^{1 / 2}
$$

The tangential component of relative velocity at the rotor exit is determined from Equation (21).

$$
W_{U 2}=\left(W_{2}^{2}-C_{M 2}^{2}\right)^{1 / 2}
$$

The slip factor is the difference between the theoretical and absolute fluid tangential velocities normalized with blade peripheral speed as described by Equation (22). The slip factor is an input item and is typically from 0.93 to 0.96 for axial compressors. For centrifugal compressors the slip factor can be on the order of from 0.80 to 0.90 , depending on number of blades and exit blade angle.

$$
\delta=\frac{C_{U 2}+C_{M 2} \operatorname{Tan}\left(\beta_{\mathrm{B} 2}\right)}{U_{2}}
$$

In the design mode, the rotor exit blade angle is determined from Equation (23) in terms of the slip factor, rotor peripheral velocity and the absolute tangential and meridional velocities.

$$
\beta_{B 2}=\operatorname{Tan}^{-1}\left[\frac{\left(\delta U_{2}-C_{U 2}\right)}{C_{M 2}}\right]
$$

The relative flow angle at the rotor exit is determined from Equation (24).

$$
\beta_{F 2}=\operatorname{Tan}^{-1}\left[\frac{\left(U_{2}-C_{U 2}\right)}{C_{M 2}} \mid\right.
$$

The rotor diffusion factor at the root-mean-square radius is calculated by Equation (25).

$$
D F=1-\frac{W_{2}}{W_{1}}+\frac{\left(R_{1} C_{U 1}-R_{2} C_{U 2}\right)}{\left(R_{1}+R_{2}\right) W_{1} \sigma}
$$


The incidence at the stator vane leading edge can be estimated by Equation (26).

$$
i_{V}=\alpha_{2}-\beta_{V}
$$

The stator loss coefficient is defined by Equation (27).

$$
\omega_{V}=\frac{P_{t 4}-P_{t 2}}{P_{t 2}-P_{S 2}}
$$

The power required to drive the compressor is calculated from Equation (28).

$$
\text { Power }=\frac{\Delta H m}{550 g_{c}}
$$

The inlet guide vane setting angle versus loss of total pressure that is used by the code was determined empirically from the NASA 74-A compressor which has a flap style variable inlet guide vane, and is shown in Equation (29). As such, these losses are considered a good approximation for the 76-B compressor, which also has similar flap style inlet guide vanes. Note that these losses would likely be different for other types of variable guide vane configurations and may not provide an accurate representation of losses.

$$
\Delta P_{t}=0.0059374-.00055463747 S+.00007424 S^{2}+.000000458487 S^{3}
$$

The total pressure at the exit of the variable inlet guide vane is obtained from Equation (30).

$$
P_{t \text { exit }}=P_{t \text { inlet }}\left(1-\Delta P_{t}\right)
$$

The efficiency of the rotor as a function of incidence shown in Equation (31) was determined empirically from the Stage 37 and 74-A compressors analyzed in this report and is currently the model in the compressor code for estimating the off-design efficiency. This same model is used on all speed lines for rotor efficiency deration versus incidence.

$$
\Delta \eta=0.0006 i_{R}^{3}-0.0185 i_{R}^{2}+0.1699 i_{R}+0.5187
$$




\section{Appendix B.-NASA Stage 37 Axial Compressor (100 Percent rpm)}

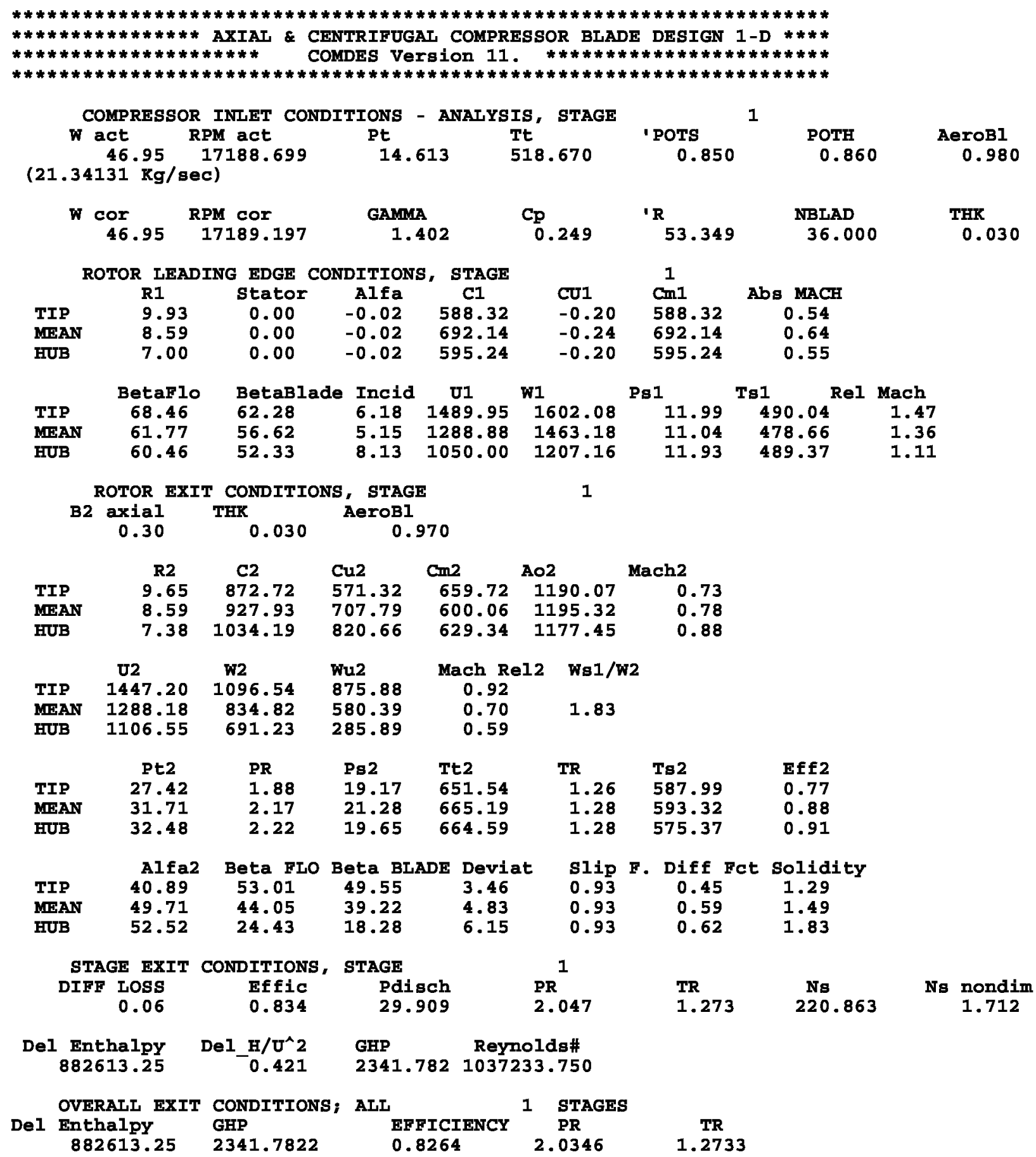





\section{Appendix C.-NASA 74-A Three Stage Axial Compressor (100 Percent rpm Geometry Reset Optimized)}

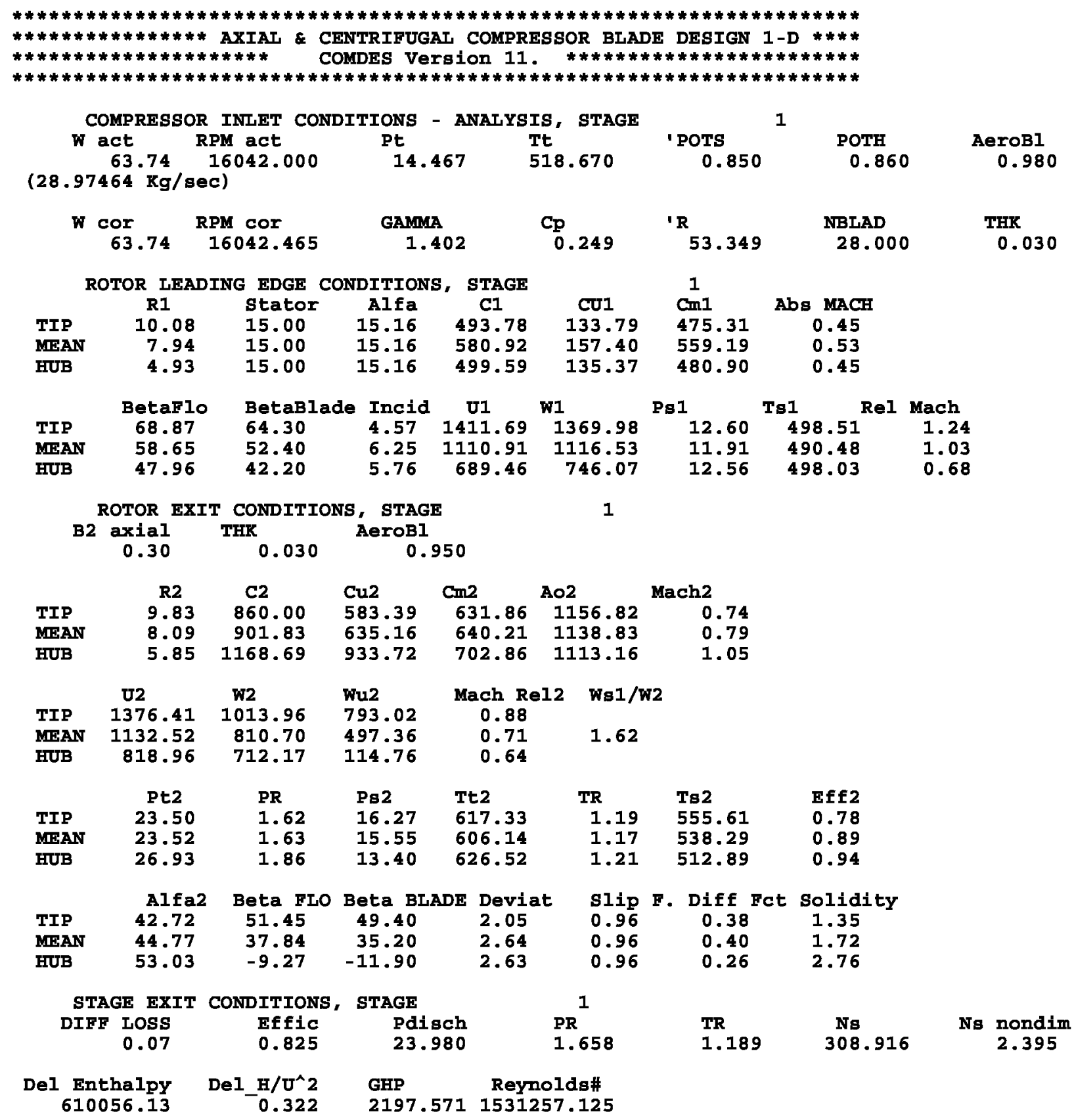




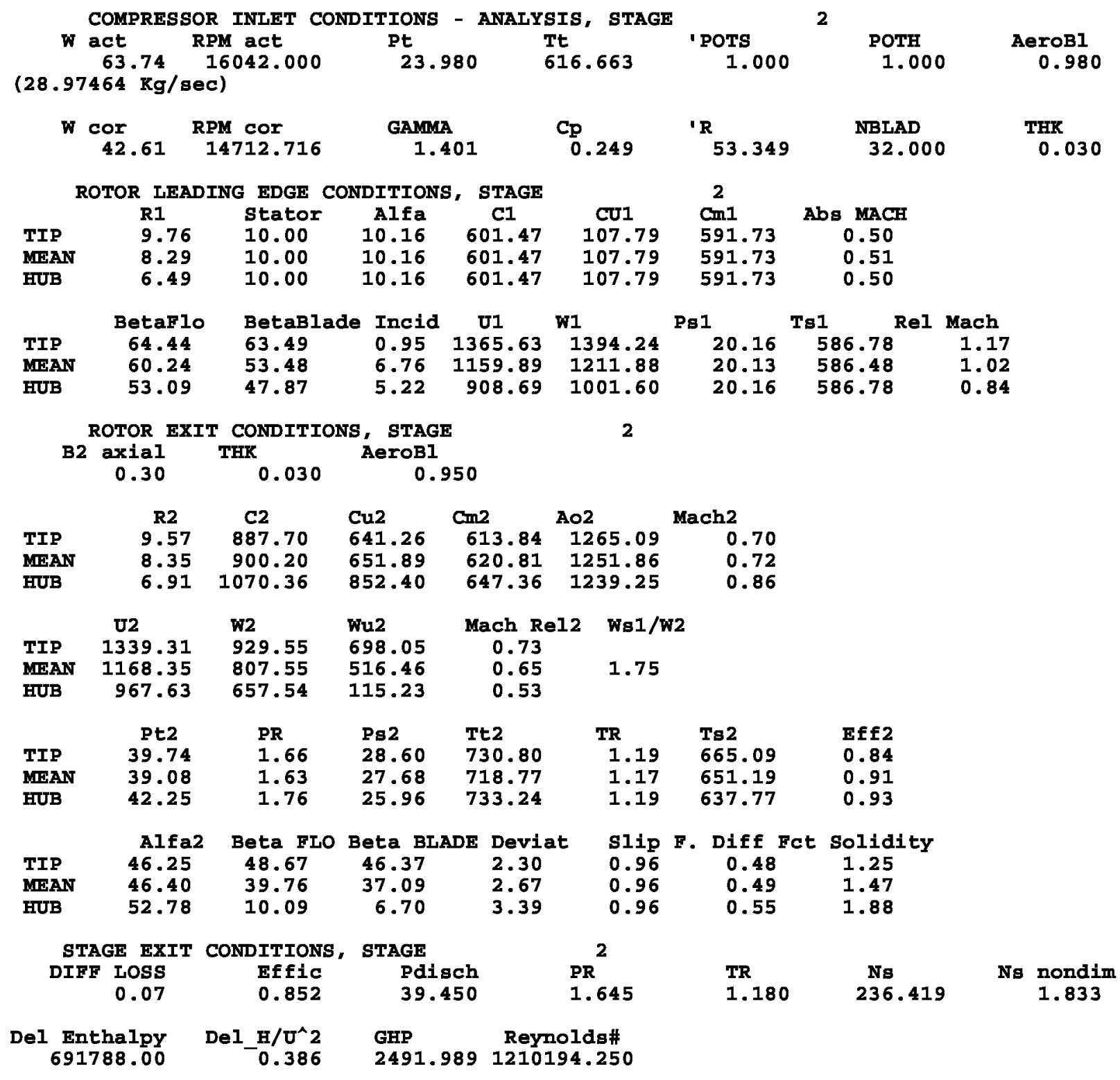




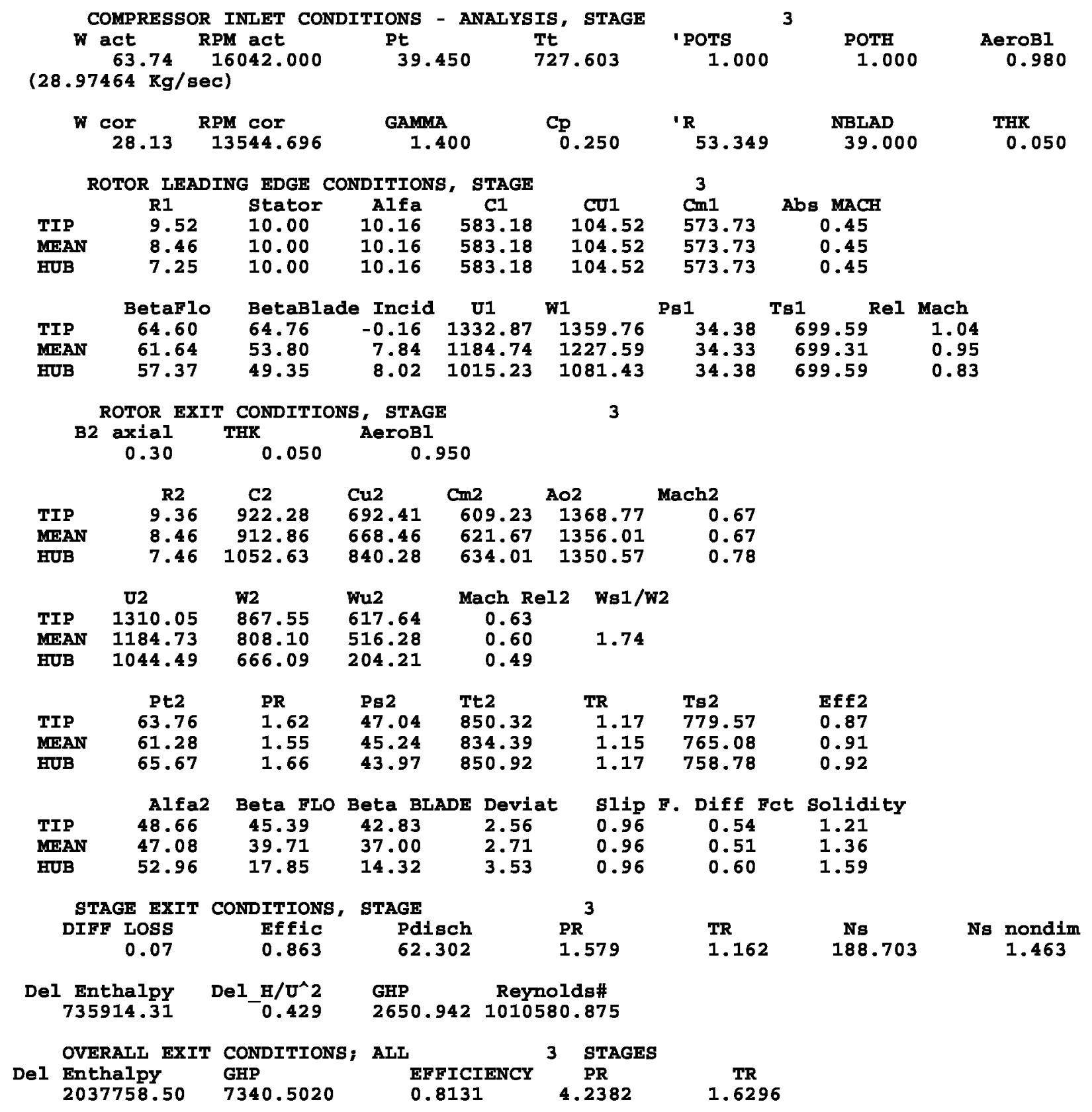





\section{Appendix D.-NASA 76-B Three Stage Axial Compressor 100 Percent rpm (Performance Estimate)}

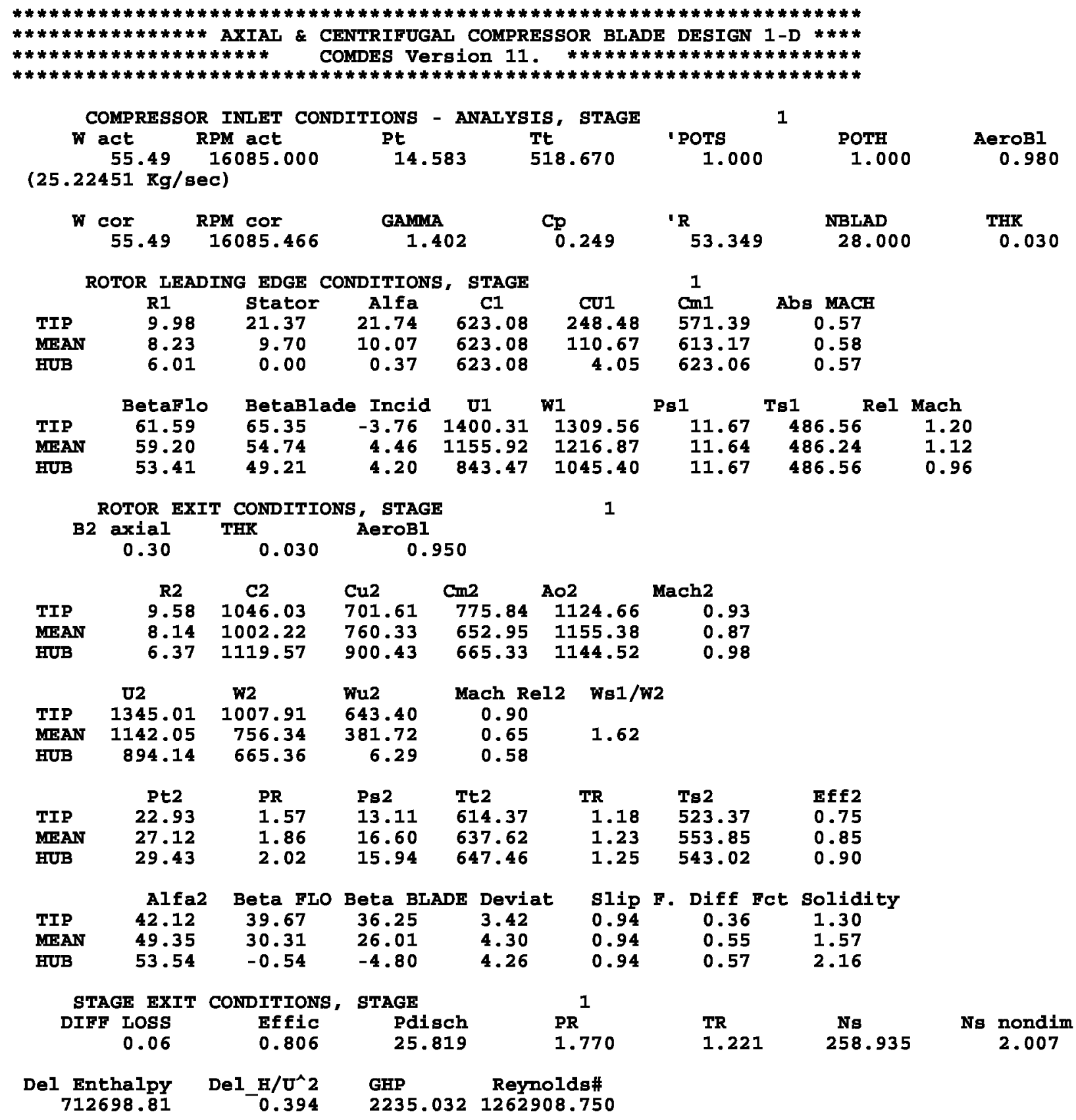




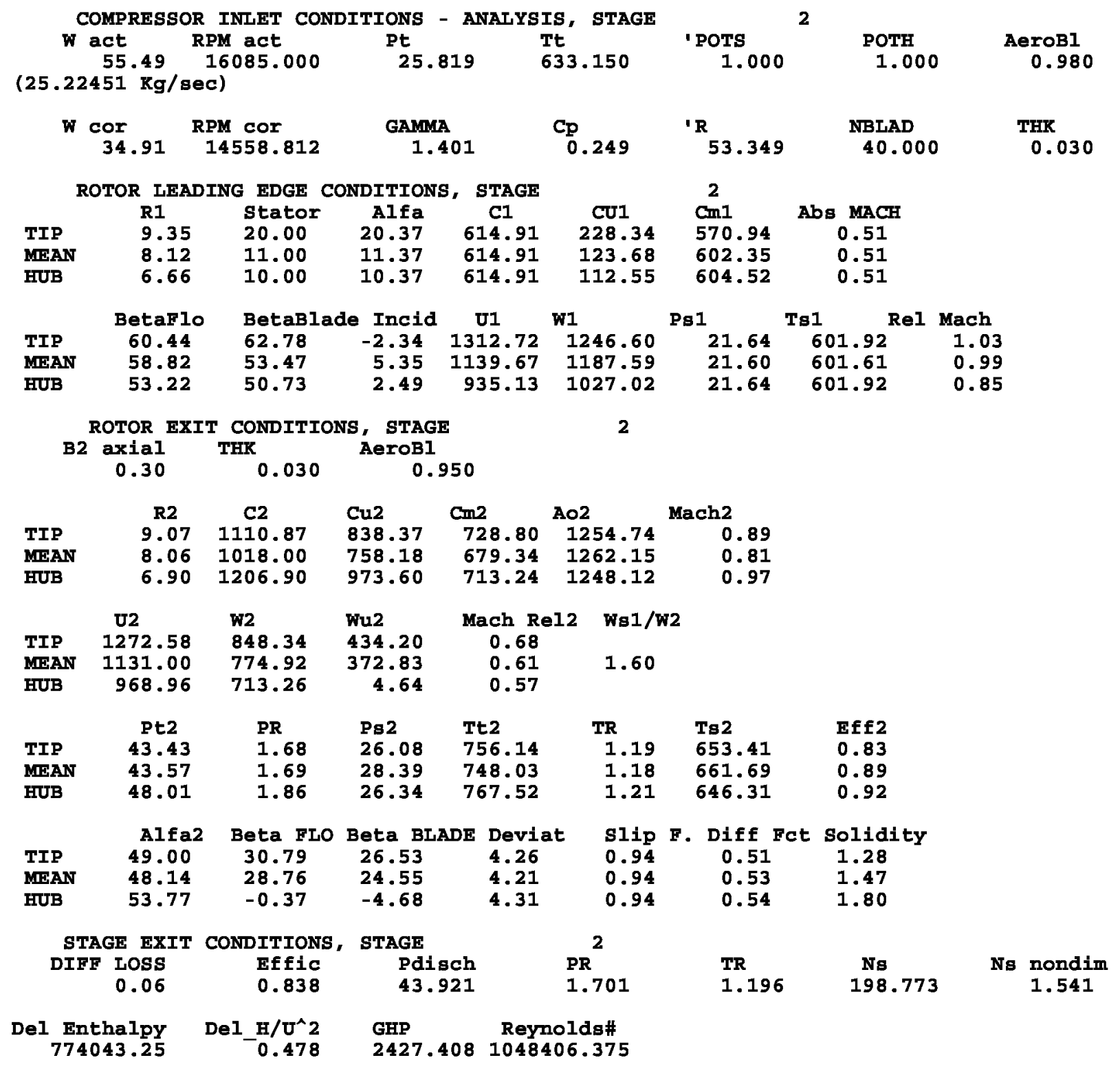




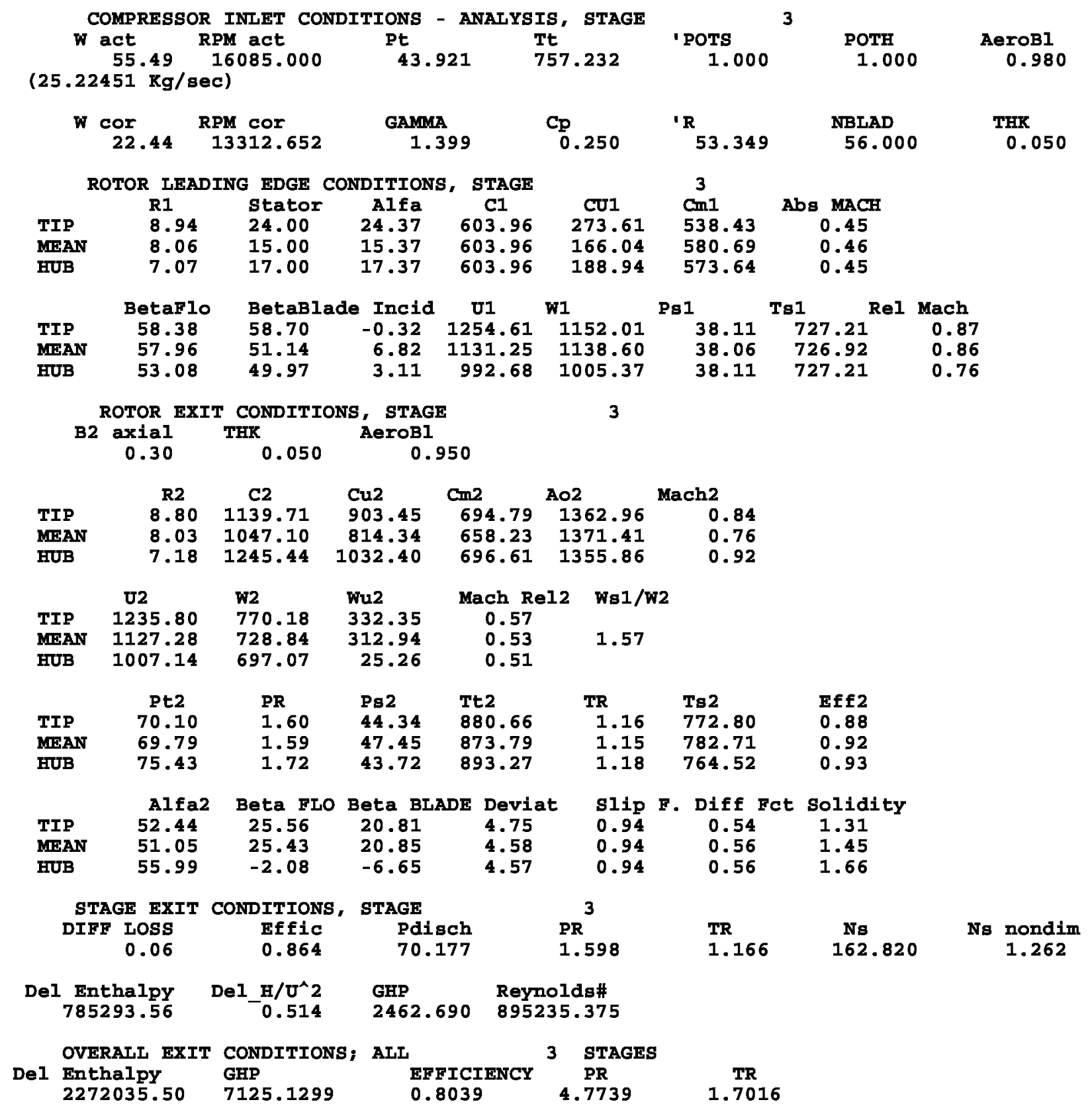




\section{References}

1. Shapiro, A.H., "The Dynamics and Thermodynamics of Compressible Fluid Flow, Volume I," The Ronald Press Co., 1953, pp. 83-88.

2. Lieblein, Schwenk, Francis, Broderick, "Diffusion Factor for Estimating Losses and Limiting Blade Loadings in Axial Flow Compressor Blade Elements," NACA RM E53D01, 1953.

3. Fowler, J.R., "GASPLUS User's Manual," NASA LEW-15091, 1994.

4. Reid, L., Moore, R.D., "Design and Overall Performance of Four Highly Loaded, High-Speed Inlet Stages for an Advanced High-Pressure-Ratio Core Compressor," NASA Technical Paper 1337, 1978.

5. Steinke, R.J., "Design of 9.271 Pressure Ratio Five Stage Core Compressor and Overall Performance for First Three Stages," NASA Technical Paper 2597, Figure 22 page 11, 1986.

6. Fabian, J.C., Thorp, S.A., Veres, J.P.,"NASA 76-B Three Stage Axial Compressor Design," NASA Technical Memorandum, (to be published).

7. Crouse, J.E., Gorrell, W.T., "Computer Program for Aerodynamic and Blading Design of Multistage Axial-Flow Compressors,” NASA TP 1946, 1981. 


\begin{tabular}{|c|c|c|}
\hline \multicolumn{2}{|c|}{ REPORT DOCUMENTATION PAGE } & $\begin{array}{l}\text { Form Approved } \\
\text { OMB No. 0704-0188 }\end{array}$ \\
\hline \multicolumn{3}{|c|}{ 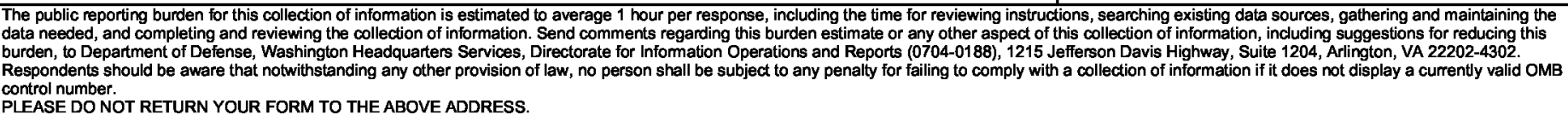 } \\
\hline $\begin{array}{l}\text { 1. REPORT DATE (DD-MM-YYYY) } \\
01-11-2009\end{array}$ & $\begin{array}{l}\text { 2. REPORT TYPE } \\
\text { Technical Memorandum }\end{array}$ & 3. DATES COVERED (From - To) \\
\hline \multirow{3}{*}{\multicolumn{2}{|c|}{$\begin{array}{l}\text { 4. TITLE AND SUBTITLE } \\
\text { Axial and Centrifugal Compressor Mean Line Flow Analysis Method }\end{array}$}} & 5a. CONTRACT NUMBER \\
\hline & & 5b. GRANT NUMBER \\
\hline & & 5c. PROGRAM ELEMENT NUMBER \\
\hline \multirow{3}{*}{\multicolumn{2}{|c|}{$\begin{array}{l}\text { 6. AUTHOR(S) } \\
\text { Veres, Joseph, P. }\end{array}$}} & 5d. PROJECT NUMBER \\
\hline & & 5e. TASK NUMBER \\
\hline & & \begin{tabular}{|l|} 
5f. WORK UNIT NUMBER \\
WBS 561581.02.08.03.21.03
\end{tabular} \\
\hline \multicolumn{2}{|c|}{$\begin{array}{l}\text { 7. PERFORMING ORGANIZATION NAME(S) AND ADDRESS(ES) } \\
\text { National Aeronautics and Space Administration } \\
\text { John H. Glenn Research Center at Lewis Field } \\
\text { Cleveland, Ohio 44135-3191 }\end{array}$} & $\begin{array}{l}\text { 8. PERFORMING ORGANIZATION } \\
\text { REPORT NUMBER } \\
\text { E-16825 }\end{array}$ \\
\hline \multirow{2}{*}{\multicolumn{2}{|c|}{$\begin{array}{l}\text { 9. SPONSORING/MONITORING AGENCY NAME(S) AND ADDRESS(ES) } \\
\text { National Aeronautics and Space Administration } \\
\text { Washington, DC 20546-0001 }\end{array}$}} & $\begin{array}{l}\text { 10. SPONSORING/MONITOR'S } \\
\text { ACRONYM(S) } \\
\text { NASA; AIAA }\end{array}$ \\
\hline & & $\begin{array}{l}\text { 11. SPONSORING/MONITORING } \\
\text { REPORT NUMBER } \\
\text { NASA/TM-2009-215585; AIAA-2009- } \\
1641\end{array}$ \\
\hline \multicolumn{3}{|c|}{$\begin{array}{l}\text { 12. DISTRIBUTION/AVAILABILITY STATEMENT } \\
\text { Unclassified-Unlimited } \\
\text { Subject Categories: } 07,02 \text {, and } 05 \\
\text { Available electronically at http://gltrs.grc.nasa.gov } \\
\text { This publication is available from the NASA Center for AeroSpace Information, 443-757-5802 }\end{array}$} \\
\hline
\end{tabular}

\section{SUPPLEMENTARY NOTES}

\section{ABSTRACT}

This paper describes a method to estimate key aerodynamic parameters of single and multistage axial and centrifugal compressors. This mean-line compressor code COMDES provides the capability of sizing single and multistage compressors quickly during the conceptual design process. Based on the compressible fluid flow equations and the Euler equation, the code can estimate rotor inlet and exit blade angles when run in the design mode. The design point rotor efficiency and stator losses are inputs to the code, and are modeled at off design. When run in the off-design analysis mode, it can be used to generate performance maps based on simple models for losses due to rotor incidence and inlet guide vane reset angle. The code can provide an improved understanding of basic aerodynamic parameters such as diffusion factor, loading levels and incidence, when matching multistage compressor blade rows at design and at part-speed operation. Rotor loading levels and relative velocity ratio are correlated to the onset of compressor surge. NASA Stage 37 and the three-stage NASA 74-A axial compressors were analyzed and the results compared to test data. The code has been used to generate the performance map for the NASA 76-B three-stage axial compressor featuring variable geometry. The compressor stages were aerodynamically matched at off-design speeds by adjusting the variable inlet guide vane and variable stator geometry angles to control the rotor diffusion factor and incidence angles.

\section{SUBJECT TERMS}

Compressors; Turbocompressors; Simulation; Computational fluid dynamic; Turbomachinery

\begin{tabular}{|c|c|c|c|c|c|}
\hline \multicolumn{3}{|c|}{ 16. SECURITY CLASSIFICATION OF: } & \multirow{2}{*}{$\begin{array}{l}\text { 17. LIMITATION OF } \\
\text { ABSTRACT } \\
\text { UU }\end{array}$} & \multirow{2}{*}{$\begin{array}{l}\text { 18. NUMBER } \\
\text { OF } \\
\text { PAGES } \\
36\end{array}$} & \multirow{2}{*}{$\begin{array}{l}\text { 19a. NAME OF RESPONSIBLE PERSON } \\
\text { STI Help Desk (email:help@sti.nasa.gov) } \\
\text { 19b. TELEPHONE NUMBER (include area code) } \\
\text { 443-757-5802 }\end{array}$} \\
\hline $\begin{array}{l}\text { a. REPORT } \\
\text { U }\end{array}$ & $\begin{array}{l}\text { b. ABSTRACT } \\
U\end{array}$ & $\begin{array}{l}\text { c. THIS } \\
\text { PAGE } \\
\text { U }\end{array}$ & & & \\
\hline
\end{tabular}


